\title{
Entropy Generation Analysis of Power-Law Non-Newtonian Fluid Flow Caused by Micropatterned Moving Surface
}

\author{
M. H. Yazdi, ${ }^{1,2,3}$ I. Hashim, ${ }^{4,5}$ A. Fudholi, ${ }^{2}$ P. Ooshaksaraei, ${ }^{2}$ and K. Sopian ${ }^{2}$ \\ ${ }^{1}$ Faculty of Science, Technology, Engineering and Mathematics, INTI International University, \\ 71800 Nilai, Negeri Sembilan, Malaysia \\ ${ }^{2}$ Solar Energy Research Institute (SERI), Universiti Kebangsaan Malaysia, 43600 Bangi, Malaysia \\ ${ }^{3}$ Department of Mechanical Engineering, Science and Research Branch, Islamic Azad University, \\ Neyshabur 9319313668, Razavi Khorasan, Iran \\ ${ }^{4}$ School of Mathematical Sciences, Faculty of Science \& Technology, Universiti Kebangsaan Malaysia, 43600 Bangi, Selangor, Malaysia \\ ${ }^{5}$ Department of Mathematics, Faculty of Science, King Abdulaziz University, P.O. Box 80257, Jeddah 21589, Saudi Arabia
}

Correspondence should be addressed to M. H. Yazdi; mohammadhossein.yazdi@gmail.com

Received 9 March 2014; Accepted 17 June 2014; Published 17 July 2014

Academic Editor: Zhijun Zhang

Copyright (C) 2014 M. H. Yazdi et al. This is an open access article distributed under the Creative Commons Attribution License, which permits unrestricted use, distribution, and reproduction in any medium, provided the original work is properly cited.

In the present study, the first and second law analyses of power-law non-Newtonian flow over embedded open parallel microchannels within micropatterned permeable continuous moving surface are examined at prescribed surface temperature. A similarity transformation is used to reduce the governing equations to a set of nonlinear ordinary differential equations. The dimensionless entropy generation number is formulated by an integral of the local rate of entropy generation along the width of the surface based on an equal number of microchannels and no-slip gaps interspersed between those microchannels. The velocity, the temperature, the velocity gradient, and the temperature gradient adjacent to the wall are substituted into this equation resulting from the momentum and energy equations obtained numerically by Dormand-Prince pair and shooting method. Finally, the entropy generation numbers, as well as the Bejan number, are evaluated. It is noted that the presence of the shear thinning (pseudoplastic) fluids creates entropy along the surface, with an opposite effect resulting from shear thickening (dilatant) fluids.

\section{Introduction}

The method of thermodynamic optimization or entropy generation minimization is an active field at the interface between heat transfer, engineering thermodynamics, and fluid mechanics. The entropy generation analysis of nonNewtonian fluid flow over surface has many significant applications in thermal engineering and industries. Applications of horizontal surfaces can also be found in various fluid transportation systems. Before considering entropy generation analysis, the flow and heat transfer part should be evaluated first. As explained, non-Newtonian fluid flow has received considerable attention due to many important applications in both micro- [1-8] and macroscale technologies [9]. Examples of non-Newtonian fluids include grease, cosmetic products, blood, body fluids, and many others
[10]. Based on the macroscale applications, the problem can receive considerable attention because of the wide use of nonNewtonians in food engineering, power engineering, and many industries such as extrusion of polymer fluids, polymer solutions used in the plastic processing industries, rolling sheet drawn from a die, drying of paper, exotic lubricants, food stuffs, and many others [11] which in most of them a cooling system is required. The analysis of the flow field in boundary layer adjacent to the wall is very important in the present problem and is an essential part in the area of fluid dynamics and heat transfer. The partial slip occurs in the most of the microfluidic devices since slip flow happens if the characteristic size of the flow system is small or the flow pressure is very low [12]. A literature survey indicates that there has been an extensive research presented regarding the slip boundary layer flow over surface in various situations. 
Regarding external slip flow regimes based on horizontal surfaces, Yazdi et al. [13] have investigated the slip boundary layer flow past flat surface. They examined the velocity slip effects on both gas and liquid flows. They also showed that hydrodynamic slip can enhance heat transfer rate in liquid flow case. In a later work, they [14] investigated the effect of permeability parameter on the slip flow regime. Further, they $[15,16]$ investigated the study of slip MHD flow and heat transfer over an accelerating continuous moving surface. Besides, Mahmoud and Waheed [17] performed the flow and heat transfer characteristics of MHD mixed convection fluid flow past a stretching surface with slip velocity at the surface and heat generation (absorption). Later, Yazdi et al. [18] have evaluated the effects of viscous dissipation on the slip MHD flow and heat transfer past a permeable surface with convective boundary conditions. They demonstrated that the magnetic lines of force can increase fluid motion inside of the boundary layer by affected free stream velocity.

Many of the non-Newtonian fluids seen in chemical engineering processes are known to follow the empirical Ostwaldde Waele power-law model. This is the simplest and most common type of power-law fluid which has received special attraction from the researchers in the field. The rheological equation of the state between the stress components $\tau_{i j}$ and strain components $e_{i j}$ is defined by Vujanovic et al. [19]

$$
\tau_{i j}=-p \delta_{i j}+k_{N}\left|\sum_{m=1}^{3} \sum_{l=1}^{3} e_{l m} e_{l m}\right|^{(n-1) / 2} e_{i j},
$$

where $p$ is the pressure, $\delta_{i j}$ is Kroneckar delta, and $k_{N}$ and $n$ are, respectively, the consistency coefficient and power-law index of the fluid. Such fluids are known as power-law fluid. For $n>1$, fluid is said to be dilatant or shear thickening; for $n<1$, the fluid is called shear thinning or pseudoplastic fluid, and for $n=1$, the fluid is simply the Newtonian fluid. Several fluids studied in the literature suggest the range $0<$ $n<2$ for the value of power-law index $n$ [20]. The theory of boundary layer was applied to power-law fluids by Schowalter [21]. Besides, Acrivos et al. [22] investigated the momentum and heat transfer in laminar boundary layer flow of nonNewtonian fluids over surface. Later, flow and heat transfer in a power-law fluid over a nonisothermal stretching sheet were evaluated by Hassanien et al. [23]. In their results, the friction factor and heat transfer rate exhibit strong dependence on the fluid parameters. Later, an analytical solution of MHD boundary layer flow of a non-Newtonian power-law fluid past a continuously moving surface studied by M. A. A. Mahmoud and M. A.-E. Mahmoud [24]. The effects of the power lawindex $(n)$ on the velocity profiles and the skin-friction were studied by them. Recently, analytical solutions for a nonlinear problem arising in the boundary layer flow of power-law fluid over a power-law stretching surface studied by Jalil et al. [25]. Their results show that the skin friction coefficient decreases with the increase of rheological properties of non-Newtonian power-law fluids. Furthermore, Mahmoud [26] examined the effect of partial slip on non-Newtonian power-law fluid over a moving permeable surface with heat generation. The problem was applied at constant temperature wall. It was found that the velocity reduced as either the slip parameter or the suction parameter was increased. Moreover, unsteady MHD mixed convective boundary layer slip flow and heat transfer with thermal radiation and viscous dissipation investigated by Ibrahim and Shanker [27]. More recently, slip effects on MHD flow over an exponentially stretching sheet with suction/blowing and thermal radiation were investigated by Mukhopadhyay [28] where the viscous dissipation and joule heating were not considered. Besides, Vajravelu et al. [29] investigated MHD flow and heat transfer of an Ostwaldde Waele fluid over an unsteady stretching surface. It was found that shear thinning reduces the wall shear stress. Regarding entropy generation analysis of external flow and heat transfer over different surface structures, there are several researches which should be considered here. In a comprehensive research study, the second law characteristics of heat transfer and fluid flow due to forced convection of steady-laminar flow of an incompressible fluid inside channel with circular cross-section and channel made of two parallel plates was analyzed by Mahmud and Fraser [30]. The analysis of the second law of thermodynamics due to viscoelastic MHD flow over a continuous moving surface was presented by Aiboud and Saouli [31]. They indicated that the surface acts as a strong source of irreversibility and the entropy generation number increases with the increase of magnetic parameter. Later, the effect of blowing and suction on entropy generation analysis of laminar boundary layer flow over an isothermal permeable flat plate was studied by Réveillère and Baytaş [32]. Recently, Eegunjobi and Makinde [33] examined the effects of the thermodynamic second law on steady flow of an incompressible electrically conducting fluid in a channel with permeable walls and convective surface boundary conditions. In macroscale systems, surface shape optimization has been effectively applied for flow and heat transfer control. Both square and triangular grooves along the surface have been investigated for boundary layer flow and heat transfer control. An experimental investigation was carried out to examine the effects of axisymmetric grooves of square or triangular cross-section on the impinging jet-to-wall heat transfer, under constant wall temperature conditions [34]. They concluded significant heat transfer enhancements, up to $81 \%$ as compared with the smooth plate reference case. Maximum was obtained for square cross-section grooves. Thus, square grooves have been found to be more efficient, for heat transfer increase, than those with a triangular profile. The shape optimization is also applicable in microscale systems. As we know, it is frequently desirable to reduce the frictional pressure drop in microchannel flows. Lim and Choit [35] designed optimally curved microchannels due to shape optimization effects on pressure drop. They considered two different wall types such as hydrophobic and hydrophilic walls. Reynolds numbers of $0.1,1$, and 10 were studied. It was observed that microchannel shape optimization could reduce the pressure drop by up to about $20 \%$.

Entropy generation analysis based surface microprofiling is called EBSM. As a shape optimization technique, EBSM considers optimal microprofiling of a micropatterned surface to minimize entropy production. Dissimilar to past techniques of modelling surface roughness by an effective friction factor, the new method of EBSM develops analytical 
solutions for the embedded microchannels (microgrooves) to give more carefully optimized surface characteristics. EBSM was developed for the first time by Naterer [36] who proposed surface microprofiling to reduce energy dissipation in convective heat transfer. This method includes local slip-flow conditions within the embedded open microchannels and thus tends to drag reduction and lower exergy losses along the surface [36, 37]. In another work, Naterer [38], specifically, concentrated on open parallel microchannels surface design. He attempted to optimize the microscale features of the surface. The optimized number of channels spacing between microchannels and aspect ratios was modelled to give an effective compromise between friction and heat transfer irreversibilities. His results suggested that embedded surface microchannels can successfully reduce loss of available energy in external forced convection problems of viscous gas flow over a flat surface [38]. In another comprehensive study, Naterer and Chomokovski [39] developed this technique to converging surface microchannels for minimized friction and thermal irreversibilities. His results suggest that the embedded converging surface microchannels have the potential to reduce entropy generation in boundary layer flow with convective heat transfer. It was noted that the EBSM technique can be appropriately extended to more complex geometries. In a subsequent novel work, Naterer et al. [40] applied both experimentally and numerically this method to the special application of aircraft intake deicing. Thus, a new surface microprofiling technique for reducing exergy losses and controlling near-wall flow processes, particularly for anti-icing of a helicopter engine bay surface was developed. The embedded microchannels were illustrated to have convinced influences on convective heat transfer. In regard to deicing applications, the motivation was to suitably modify the convective heat transfer, or runback flow of unfrozen water, so that ice formation would be delayed or prevented. Later, a study based on liquid flow over open microchannels was investigated by Yazdi et al. [6]. In another study, they [8] presented the second law analysis of MHD flow over embedded microchannels in an impermeable surface. Later, Yazdi et al. [7] investigated entropy generation analysis of electrically conducting fluid flow over open parallel microchannels embedded within a continuous moving surface in the presence of applied magnetic field where the free stream velocity was stationary and the fluid was moving by an external surface force. Recently, they [41] have evaluated the reduction of entropy generation by embedded open parallel microchannels within the permeable surface in order to reach a liquid transportation design in microscale MHD systems. A Newtonian fluid has been considered in previous EBSM researches.

Recently, the use of open microchannels instead of the usual closed microchannels has been recommended, since the open microchannels are open to the ambient air on the top side, which can offer advantages, such as maintaining the physiological conditions for normal cell growth and introducing accurate amounts of chemical and biological materials [42-44]. Taking advantages of microfabrication techniques due to making appropriate slip boundary condition along

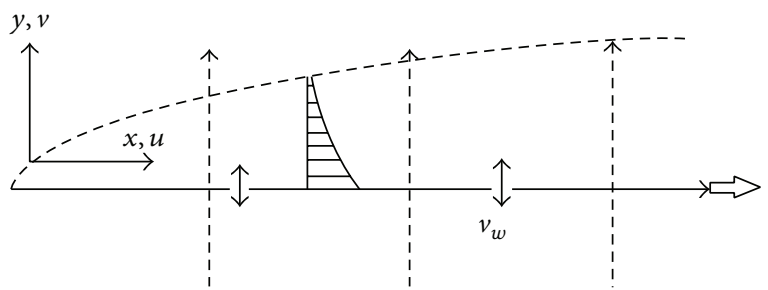

(a)

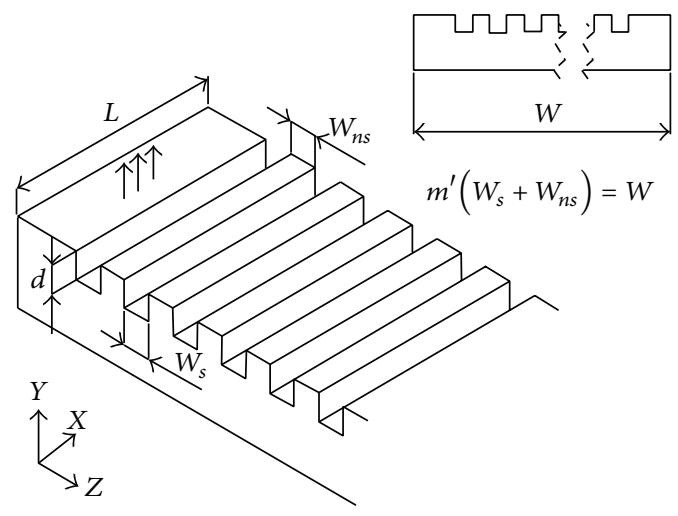

(b)

FIGURE 1: (a) Physical model of fluid flow. (b) Schematic diagram of embedded surface microchannels (the subscripts of $n s$ and $s$ refer to no-slip and slip conditions, resp.).

hydrophobic open microchannels together with biotechnological application areas of open microchannels motivates us to consider carefully a practical design for controlling the entropy production of various non-Newtonians in microscale systems. There have been many theoretical problems developed for entropy generation analysis of boundary layer flow. However, to the best of our knowledge, no investigation has been made yet to evaluate EBSM in a non-Newtonian fluid system. The EBSM technique is recommended here, as a proper surface shape technique due to valuation of entropy production in microscale systems. Such innovations can examine energy efficiency of existing microfluidic systems by embedding microchannels within permeable surfaces.

\section{Mathematical Formulation}

2.1. Flow and Heat Transfer Analysis. The flow configuration is illustrated in Figure 1(a). First, we prepare the flow and heat transfer mathematical formulation of steady, 2D, laminar slip boundary layer flow of a power-law non-Newtonian fluid over continuously permeable moving surface with constant velocity $U$ at prescribed surface temperature in the presence of viscous dissipation (see Figure 1(a)). After that, the utilization of the second law of thermodynamics is focused on EBSM which requires simultaneous modeling of the slip and no-slip boundary condition along the width of the micropatterned surface (see Figure 1(b)). It is assumed that the width of the surface consists of a specific number of open microchannels and the base sections $(m)$, each of which has its own width. Moreover, a no-slip condition 
is applied between open microchannels, whereas a slip condition is applied to the open parallel microchannels. Thus, in the present micropatterned surface design, based on EBSM techniques [7, 37, 39-41], the slip boundary condition is applied inside the open microchannels. Experimental evidence recommends that, for water flowing through a microchannel, the surface of which is coated with a $2.3 \mathrm{~nm}$ thick monolayer of hydrophobic octadecyltrichlorosilane, an apparent hydrodynamic slip is measured just above the solid surface. This velocity is about $10 \%$ of the free-stream velocity [45].

Based on the assumptions of the problem, non-Newtonian fluid is a continuum and an incompressible fluid. The positive $y$-coordinate is considered normal to the $x$ coordinate. The corresponding velocity components in the $x$ and $y$ directions are $u$ and $v$, respectively. $x$ is the coordinate along the plate measured from the leading edge. The positive $y$-coordinate is measured perpendicular to the $x$-coordinate in the outward direction towards the fluid. The corresponding velocity components in the $x$ and $y$ directions are denoted as $u$ and $v$, respectively. A permeable surface is considered here at prescribed surface temperature (PST), $T_{\text {wall }}$ given by [7]

$$
y=0, \quad T=T_{\text {wall }}\left(=T_{\infty}+A x^{k^{\prime}}\right),
$$

where $A$ is a constant and $k^{\prime}$ is the surface temperature parameter at the prescribed surface temperature (PST) boundary condition. Besides, the volumetric rate of heat generation is defined as follows $[26,46,47]$ :

$$
Q= \begin{cases}Q_{0}\left(T-T_{\infty}\right), & T \geq T_{\infty} \\ 0 & T<0,\end{cases}
$$

where $Q_{0}$ is the heat generation/absorption coefficient. The continuity, momentum, and energy equations for power-law fluid in Cartesian coordinates $x$ and $y$ are

$$
\begin{gathered}
\frac{\partial u}{\partial x}+\frac{\partial v}{\partial y}=0 \\
u \frac{\partial u}{\partial x}+v \frac{\partial u}{\partial y}=\frac{\mu}{\rho} \frac{\partial}{\partial y}\left(\left|\frac{\partial u}{\partial y}\right|^{n-1} \frac{\partial u}{\partial y}\right), \\
u \frac{\partial T}{\partial x}+v \frac{\partial T}{\partial y}=\alpha \frac{\partial^{2} T}{\partial y^{2}}+\frac{\mu}{\rho c_{p}}\left|\frac{\partial u}{\partial y}\right|^{n+1}+\frac{Q_{0}\left(T-T_{\infty}\right)}{\rho c_{p}}
\end{gathered}
$$

where $n, \rho, \alpha$, and $\mu$ are the power-law index parameter, the fluid density, the thermal diffusivity, and the consistency index for non-Newtonian viscosity, respectively. $T$ is the temperature of the fluid and $c_{p}$ is the specific heat at constant pressure. The associated boundary conditions are given by

$$
\begin{gathered}
y=0 \Longrightarrow u=U+u_{s}=U+\left.l_{1}\left(\left|\frac{\partial u}{\partial y}\right|^{n-1} \frac{\partial u}{\partial y}\right)\right|_{w}, \\
v=v_{w}, \quad T=T_{w}\left(=T_{\infty}+A x^{k^{\prime}}\right) \\
y \longrightarrow \infty \Longrightarrow u=0, \quad T=T_{\infty},
\end{gathered}
$$

where $u_{s}$ is the partial slip based on power-law nonNewtonian fluid adjacent to the wall and $l_{1}$ is the slip length having dimension of length. The equation of continuity is integrated by the introduction of the stream function $\psi(x, y)$. The stream function satisfies the continuity equation (4) and is defined by

$$
u=\frac{\partial \psi}{\partial y}, \quad v=\frac{\partial \psi}{\partial x}
$$

Similarity solution method permits transformation of the partial differential equations (PDE) associated with the transfer of momentum and thermal energy to ordinary differential equations (ODE) containing associated parameters of the problem by using nondimensional parameters. Applying similarity method, the fundamental equations of the boundary layer are transformed to ordinary differential ones. The stream function, $\psi$, which is a function of $x$ and $y$, can be expressed as a function of $x$ and $\eta$, if the similarity solution exists. The mathematical analysis of the problem can be simplified by introducing the following dimensionless coordinates:

$$
\begin{gathered}
f^{\prime}(\eta)=\frac{u}{U} \quad \eta=y\left(\frac{U^{2-n}}{v_{\infty} x}\right) \\
\theta(\eta)=\frac{T-T_{\infty}}{T_{w}-T_{\infty}}, \quad \psi(\eta)=\left(\nu_{\infty} x U^{2 n-1}\right)^{1 /(n+1)} f(\eta),
\end{gathered}
$$

where $v_{\infty}$ is the non-Newtonian kinematic viscosity, $f(\eta)$ is the dimensionless stream function, $\theta(\eta)$ is the dimensionless temperature of the fluid in the boundary layer region, and $\psi$ is stream function as a function of $x$ and $\eta$. By means of above similarity variables, non-Newtonian fluid velocity adjacent to the wall can be defined as follows:

$$
f^{\prime}(0)=1+K\left(f^{\prime \prime}(0)\left|f^{\prime \prime}(0)\right|^{n-1}\right),
$$

where $K$ is the slip coefficient given by

$$
K=\frac{l_{1}}{U}\left(\frac{U^{3}}{v_{\infty} x}\right)^{n /(n+1)} .
$$

The momentum and energy equations and the associated boundary conditions reduce to the following system of similarity equations:

$$
\begin{gathered}
n(n+1)\left|f^{\prime \prime}\right|^{n-1} f^{\prime \prime \prime}+f f^{\prime \prime}=0, \\
\theta^{\prime \prime}+\frac{\operatorname{Pr}}{n+1} f \theta^{\prime}+\operatorname{PrEc}\left|f^{\prime \prime}\right|^{n+1}+\operatorname{Pr} \theta-\operatorname{Pr} k^{\prime} f^{\prime} \theta=0 .
\end{gathered}
$$

The associated boundary conditions are given by

$$
\begin{aligned}
\eta=0 \Longrightarrow & \left\{\begin{array}{l}
f^{\prime}(0)=1+K\left(f^{\prime \prime}(0)\left|f^{\prime \prime}(0)\right|^{n-1}\right) \\
f(0)=f_{w} \\
\theta(0)=1
\end{array}\right. \\
& \eta \infty \begin{array}{l}
f^{\prime}(\infty)=0 \\
\theta(\infty)=0,
\end{array}
\end{aligned}
$$


where $s, f_{w}$, Pr, and Ec show the heat generation/absorption parameter, the suction/injection parameter, the modified local non-Newtonian Prandtl number, and the Eckert number, respectively. Accordingly, the involved parameters of the problem are defined by

$$
\begin{aligned}
& K=\frac{l_{1}}{U}\left(\frac{U^{3}}{v_{\infty} x}\right)^{n /(n+1)}, f_{w}=\frac{-(n+1) x^{n /(n+1)} v_{w}}{\left(\nu_{\infty} U^{2 n-1}\right)^{1 /(n+1)}} \\
& \operatorname{Pr}=\frac{U}{\alpha x}\left(\frac{U^{2-n}}{v_{\infty} x}\right)^{-2 /(n+1)}, \quad \mathrm{Ec}=\frac{U^{2}}{A x^{k^{\prime}} c_{p}}, \quad s=\frac{Q_{0} x}{U \rho c_{p}} .
\end{aligned}
$$

Suction/injection parameter $f_{w}$ determines the transpiration rate along the surface with $f_{w}>0$ for suction, $f_{w}<0$ for injection, and $f_{w}=0$ corresponding to an impermeable surface. The one-way coupled equations (12) are solved numerically by using the explicit Runge-Kutta $(4,5)$ formula, the Dormand-Prince pair, and shooting method, subject to the boundary conditions (13). Thus, the local skin friction coefficient and the local Nusselt number exhibit dependence on the involved parameters of the problem as follows:

$$
\begin{aligned}
C_{f x} & =-\frac{2 \tau_{w}}{\rho U^{2}}=-2 \operatorname{Re}^{-1 /(n+1)} f^{\prime \prime}(0)\left|f^{\prime \prime}(0)\right|^{n-1}, \\
N u_{x} & =\frac{-\left.x(\partial T / \partial y)\right|_{y=0}}{T_{w}-T_{\infty}}=\operatorname{Re}^{1 /(n+1)}\left|\theta^{\prime}(0)\right|,
\end{aligned}
$$

where $\operatorname{Re}=\rho U^{2-n} x^{n} / \mu$ refers to the local Reynolds number.

2.2. Entropy Generation Analysis. Entropy generation analysis concerned with the power-law non-Newtonian fluid flow over open parallel microchannels embedded within a continuously permeable moving surface at prescribed surface temperature in the presence of viscous dissipation. Thus, heat transfer $\left(S_{T}^{\prime \prime \prime}\right)$ and friction irreversibilities $\left(S_{F}^{\prime \prime \prime}\right)$ are included within the local volumetric rate of entropy generation. The rate of entropy generation will be obtained based on the previous solutions of the boundary layer for fluid velocity and temperature. According to Woods [48], Khan and Gorla [49], and Hung [50], the local volumetric rate of entropy generation for power-law non-Newtonian flow is given by

$$
\begin{aligned}
S_{g}^{\prime \prime \prime} & =\frac{k_{\infty}}{T_{\infty}^{2}}\left[\left(\frac{\partial T}{\partial x}\right)^{2}+\left(\frac{\partial T}{\partial y}\right)^{2}\right]+\frac{\mu}{T_{\infty}}\left|\frac{\partial u}{\partial y}\right|^{n+1} \\
& =S_{T}^{\prime \prime \prime}+S_{F}^{\prime \prime \prime},
\end{aligned}
$$

where $k_{\infty}$ is thermal conductivity. In the present work, the integration of the above local entropy generation is done only along the width of the surface ( $z$-direction) due to considering the impact of embedded microchannels within the permeable surface. This type of integration leads to study the effects of combined slip/no-slip conditions on local entropy generation rates. With the intention of considering the effect of the embedded open parallel microchannels with-in a permeable surface, integration over the width of the surface is applied over the local rate of entropy generation adjacent to the wall. The cross-stream $(z)$ dependence arises from interspersed no-slip (subscript $n s$ ) and slip-flow (subscript $s)$ solutions of the boundary layer equations. Therefore, the integration over the width of the surface from $0 \leq z \leq W$ consists of $m$ separate integrations over each microchannel surface width, $0 \leq z \leq W_{s}+2 d$, as well as the remaining no-slip portion of the plate, which is interspersed between these microchannels and covers a range of $0 \leq z \leq W-m W_{s}$ (see Figure 1(b)). Thus, by performing the integrations and assuming an equal number of microchannels and no-slip gaps interspersed between those microchannels (see Figure 1(b)), it can be shown that

$$
S_{g}^{\prime \prime}=S_{T}^{\prime \prime}+S_{F}^{\prime \prime}
$$

where

$$
\begin{aligned}
& S_{T}^{\prime \prime}=\int_{0}^{m\left(W_{s}+2 d\right)} S_{T, \text { slip }}^{\prime \prime \prime} d z+\int_{0}^{W-m W_{s}} S_{T, \text { no-slip }}^{\prime \prime \prime} d z \\
& S_{F}^{\prime \prime}=\int_{0}^{m\left(W_{s}+2 d\right)} S_{F, \text { slip }}^{\prime \prime \prime} d z+\int_{0}^{W-m W_{s}} S_{F, \text { no-slip }}^{\prime \prime \prime} d z .
\end{aligned}
$$

Moreover, the dimensionless local entropy generation rate is defined as a ratio of the present local entropy generation rate $S_{g}^{\prime \prime}$ and a characteristic entropy generation rate $S_{g 0}^{\prime \prime}$, called entropy generation number $N_{s}$. Here, the characteristic entropy generation rate, based on the width of the surface, is defined as

$$
S_{g_{0}}^{\prime \prime}=\frac{k_{\infty} \Delta T^{2} W}{L^{2} T_{\infty}^{2}},
$$

where $L$ is characteristic length scale. In addition, the nondimensional geometric parameters are defined as (see Figure 1(b))

$$
\lambda=\frac{W_{s}+2 d}{W}, \quad \varsigma=\frac{d}{W} .
$$

Consequently, the entropy generation number is expressed as

$$
\begin{aligned}
N_{s}= & \frac{S_{g}^{\prime \prime}}{S_{g_{0}}^{\prime \prime}} \\
= & \frac{k^{\prime 2}}{X^{2}} \theta_{s}^{2}(0)[m \lambda] \\
& +\frac{k^{\prime 2}}{X^{2}} \theta_{n s}^{2}(0)[1+2 m \varsigma-m \lambda] \\
& +\frac{\operatorname{Re}^{(2 /(n+1))}}{X^{2}} \theta_{s}^{\prime 2}(0)[m \lambda] \\
& +\frac{\operatorname{Re}(2 /(n+1))}{X^{2}} \theta_{n s}^{\prime 2}(0)[1+2 m \varsigma-m \lambda] \\
& +\frac{\operatorname{Br}^{2}}{\Omega} \frac{\operatorname{Re}}{X^{2}}\left|f_{s}^{\prime \prime}(0)\right|^{(n+1)}[m \lambda] \\
& +\frac{\operatorname{Br}^{2}}{\Omega} \frac{\operatorname{Re}}{X^{2}}\left|f_{s}^{\prime \prime}(0)\right|^{(n+1)}[1+2 m \varsigma-m \lambda],
\end{aligned}
$$




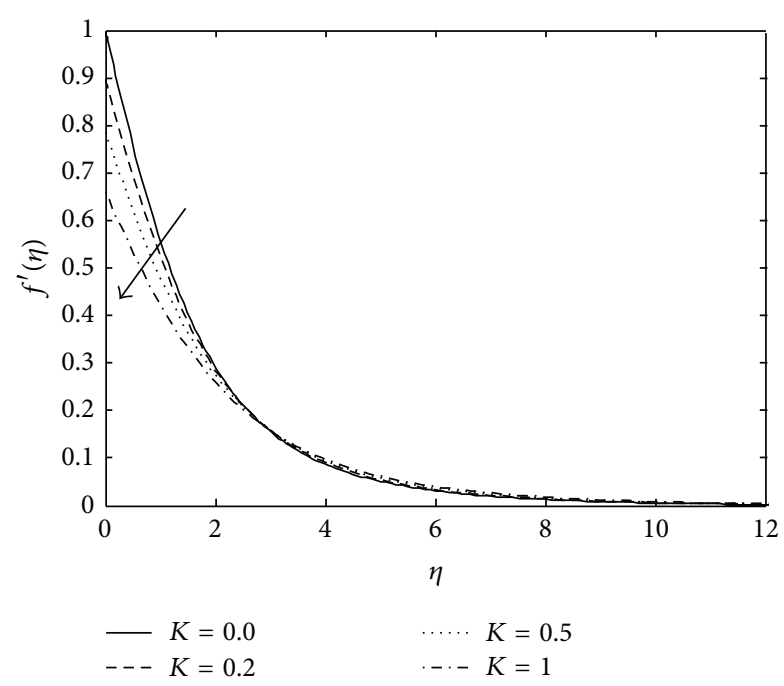

(a)

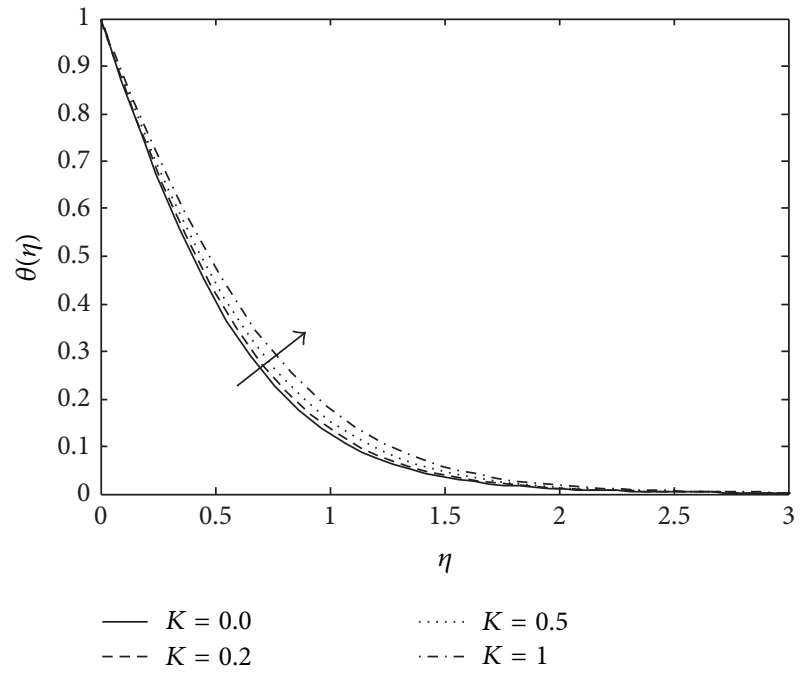

(b)

Figure 2: (a) Distribution of velocity as function of $\eta$ for various values of $K$ when $f_{w}=0.2, n=0.8$. (b) Distribution of temperature as function of $\eta$ for various values of $K$ when $f_{w}=0.2, n=0.8, s=0.1, \mathrm{Ec}=0.1, k^{\prime}=0.1$, and $\operatorname{Pr}=5$.

where $X, \mathrm{Re}, \mathrm{Br}$, and $\Omega$ are, respectively, the nondimensional surface length, the Reynolds number, the Brinkman number, and the dimensionless temperature difference. These parameters are given by the following relationships:

$$
\begin{gathered}
\mathrm{Br}=\frac{\mu U^{n+1}}{x^{n-1} k_{\infty} \Delta T}, \quad \operatorname{Re}=\frac{U^{2-n} x^{n}}{v_{\infty}}, \\
X=\frac{x}{L}, \quad \Omega=\frac{\Delta T}{T_{\infty}} .
\end{gathered}
$$

The Bejan number is defined as the ratio of heat transfer irreversibility to total irreversibility due to heat transfer and fluid friction for the power-law non-Newtonian boundary layer flow. Bejan number is given by

$$
\mathrm{Be}=\frac{\text { Heat transfer irreversibility }}{\text { Entropy generation number }}=\frac{1}{1+\Phi},
$$

where $\Phi$ is the irreversibility distribution ratio which is given by

$$
\Phi=\frac{\text { Fluid friction irreversibility }}{\text { Heat transfer irreversibility }}
$$

As the Bejan number ranges from 0 to 1 , it approaches zero when the entropy generation due to the combined effects of fluid friction and magnetic field is dominant. Similarly, $\mathrm{Be}>0.5$ indicates that the irreversibility due to heat transfer dominates, with $\mathrm{Be}=1$ as the limit at which the irreversibility is solely due to heat transfer. Consequently, $0 \leq \Phi \leq 1$ indicates that the irreversibility is primarily due to the heat transfer irreversibility, whereas for $\Phi>1$ it is due to the fluid friction irreversibility. The entropy generation number, $N_{s}$ in (21) together with Bejan number in (23) will be used for the evaluation of the present study.

\section{Results and Discussion}

The nonlinear governing partial differential equations are converted into a set of nonlinear ordinary differential ones through similarity transformations technique and then solved numerically by the Dormand-Prince pair and shooting method. The computed numerical results are shown graphically in Figures 2-14. As a test of the accuracy of the solution, a comparison between the present code results and those obtained previously is presented. Although the main focus of this paper is entropy generation, graphical presentations of local skin friction and local Nusselt number are required in order to understand the mechanisms of entropy generation along micropatterned surface. Therefore, in the first step, the effects of involved parameters of the problem on flow and heat transfer are displayed. After that, the entropy generation numbers, as well as the Bejan number, for various values of the involved parameters are evaluated.

3.1. Effects on Flow and Heat Transfer. In order to verify the accuracy of the present results, our results are compared for the local skin-friction coefficient and the local Nusselt number to those of previous studies for some special cases. Table 1 proves that the present numerical results agree well with those obtained by Sakiadis [47], Fox et al. [51], Chen [52], Jacobi [53], and Mahmoud [26] for special case of $n=1$, $K=0, M=0, f_{w}=0, \operatorname{Pr}=0.7, \mathrm{Ec}=0, s=0$, and $k^{\prime}=0.0$. Moreover, Table 2 indicates another comparison of our work for the local skin friction coefficient, $-f^{\prime \prime}(0)\left|f^{\prime \prime}(0)\right|^{(n-1)}$ and temperature gradient at the wall $\left|\theta^{\prime}(0)\right|$, respectively, with those obtained by Mahmoud [26] at special case of constant surface temperature $\left(k^{\prime}=0\right)$. Our results are found to be in excellent agreement with previous results as seen from the tabulated results.

Figure 2(a) presents the velocity profiles $f^{\prime}(\eta)$ as function of $\eta$ for various values of slip coefficient $K$ when $f_{w}=0.2$, 
TABLE 1: Comparison of the $\left|f^{\prime \prime}(0)\right|$ and $\left|\theta^{\prime}(0)\right|$ between the present results and those obtained previously for special case of $n=1, K=0$, $f_{w}=0.0, \operatorname{Pr}=0.7, \mathrm{Ec}=0.0, s=0.0$, and $k^{\prime}=0.0$.

\begin{tabular}{lcccccccc}
\hline & & $\left|f^{\prime \prime}(0)\right|$ & & & \multicolumn{3}{c}{$\left|\theta^{\prime}(0)\right|$} \\
Sakiadis [47] & Fox et al. [51] & Chen [52] & Mahmoud [26] & Present & Jacobi [53] & Chen [52] & Mahmoud [26] & Present \\
\hline 0.44375 & 0.4437 & 0.4438 & 0.44375 & 0.44375 & 0.3492 & 0.34925 & 0.34925 & 0.34925 \\
\hline
\end{tabular}

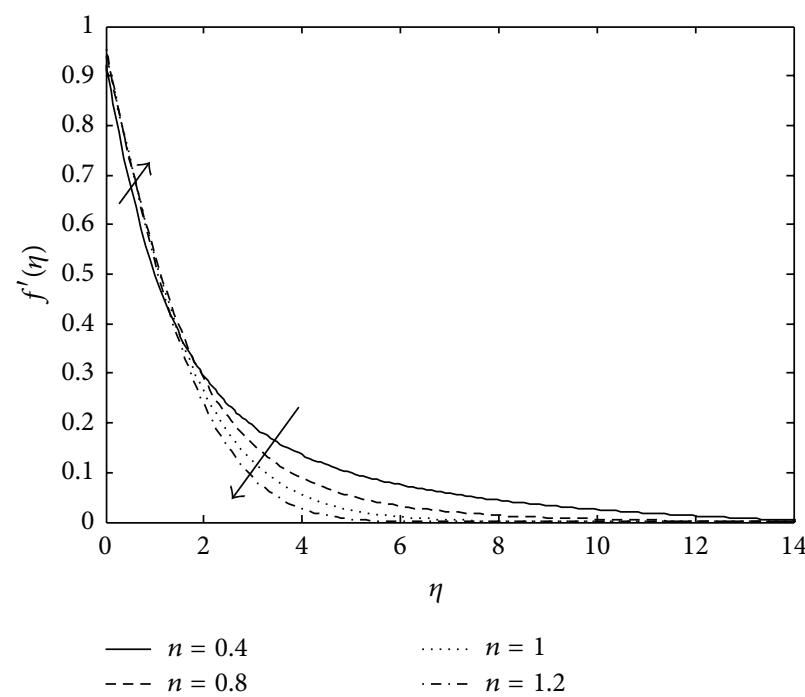

(a)

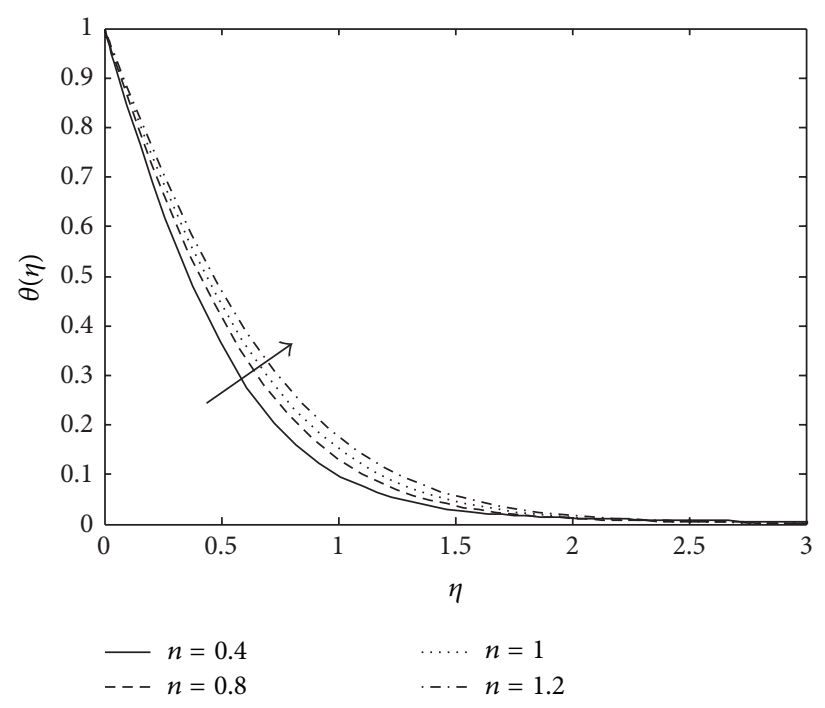

(b)

Figure 3: (a) Distribution of velocity as function of $\eta$ for various values of $n$ when $f_{w}=0.2, K=0.1$. (b) Distribution of temperature as function of $\eta$ for various values of $n$ when $f_{w}=0.2, K=0.1, s=0.1, \mathrm{Ec}=0.1, k^{\prime}=0.1$, and $\operatorname{Pr}=5$.

TABLE 2: Comparison of the skin friction $-f^{\prime \prime}(0)\left|f^{\prime \prime}(0)\right|^{n-1}$ and $\left|\theta^{\prime}(0)\right|$ between the present results and those obtained previously for special case of $n=0.8, K=0.1, \operatorname{Pr}=10, \mathrm{Ec}=0.1, s=0.1$, and $k^{\prime}=0.0$.

\begin{tabular}{lcccc}
\hline \multirow{2}{*}{$f_{w}$} & \multicolumn{2}{c}{ Mahmoud [26] } & \multicolumn{2}{c}{ Present results } \\
& $-f^{\prime \prime}(0)\left|f^{\prime \prime}(0)\right|^{n-1}$ & $\left|\theta^{\prime}(0)\right|$ & $-f^{\prime \prime}(0)\left|f^{\prime \prime}(0)\right|^{n-1}$ & $\left|\theta^{\prime}(0)\right|$ \\
\hline-0.5 & 0.3619 & 0.0303 & 0.3619 & 0.0303 \\
-0.2 & 0.4339 & 0.6604 & 0.4339 & 0.6604 \\
0.0 & 0.4865 & 1.2914 & 0.4865 & 1.2914 \\
0.2 & 0.5425 & 2.0490 & 0.5425 & 2.0490 \\
0.5 & 0.6326 & 3.3460 & 0.6326 & 3.3460 \\
\hline
\end{tabular}

$n=0.8$. The dominating nature of the slip on the boundary layer flow is clear from this figure. When partial slip occurs, the flow velocity near the surface is no longer equal to the velocity of moving surface. One can see that in the presence of slip, as $K$ increases, $f^{\prime}(\eta)$ near to the wall is decreased and then increases away from it resulting an intersection in the velocity profile. Physically, the presence of velocity slip on the moving surface within stationary fluid has tendency to decrease fluid velocity adjacent to the wall, causing the hydrodynamic boundary layer thickness to increase. In all cases the velocity vanishes at some large distance from the surface. The effect of slip coefficient $K$ on temperature profile is illustrated in Figure 2(b) when $f_{w}=0.2, n=0.8, s=0.1$,
Ec $=0.1, k^{\prime}=0.1$, and $\operatorname{Pr}=5$. It can be observed that an increase with slip coefficient tends to enhance temperature in the boundary layer. Moreover, decreasing the values of the slip coefficient leads to thinning of the thermal boundary layer thickness.

Figures 3(a) and 3(b) illustrate the influence of the powerlaw index parameter $n$, from shear-thinning fluids $(n=0.4)$ to shear-thickening fluids $(n=1.2)$ on nondimensional velocity and temperature profiles, respectively. For nonNewtonians, the slope of the shear stress versus shear rate curve will not be constant as we change the shear rate. As explained, when the viscosity decreases with increasing shear rate, we call the fluid shear thinning. Having a power-law index $n<1$ is referred as a shear-thinning fluid. Thus, a reduction in the shear layer (when compared with Newtonian fluid flow) is a characteristic feature of non-Newtonian fluids when $n<1$. One explanation of shear thinning is that asymmetric particles are progressively aligned with streamlines, an alignment that responds nearly instantaneously to changes in the imposed shear; after complete alignment at high shear the apparent viscosity becomes constant [54]. In the opposite case where the viscosity increases as the fluid is subjected to a higher shear rate, the fluid is called shear thickening having an index $n>1$ [55]. These figures indicate that the velocity profiles decrease with the increase of $n$ in velocity boundary layer but this consequence is not very noticeable adjacent to the wall (see Figure 3(a)). One can see that, in 


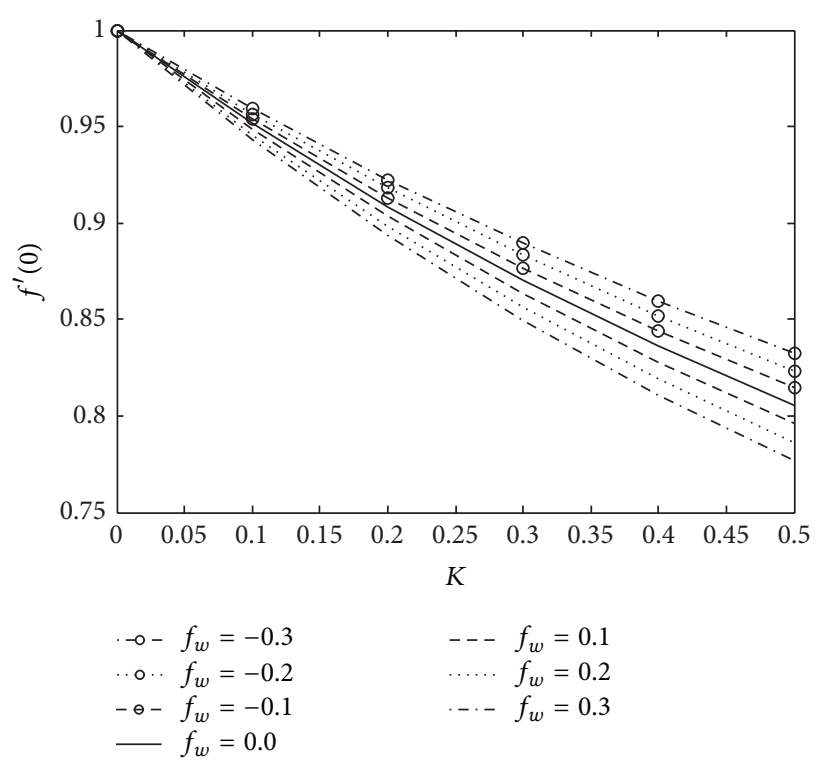

(a)

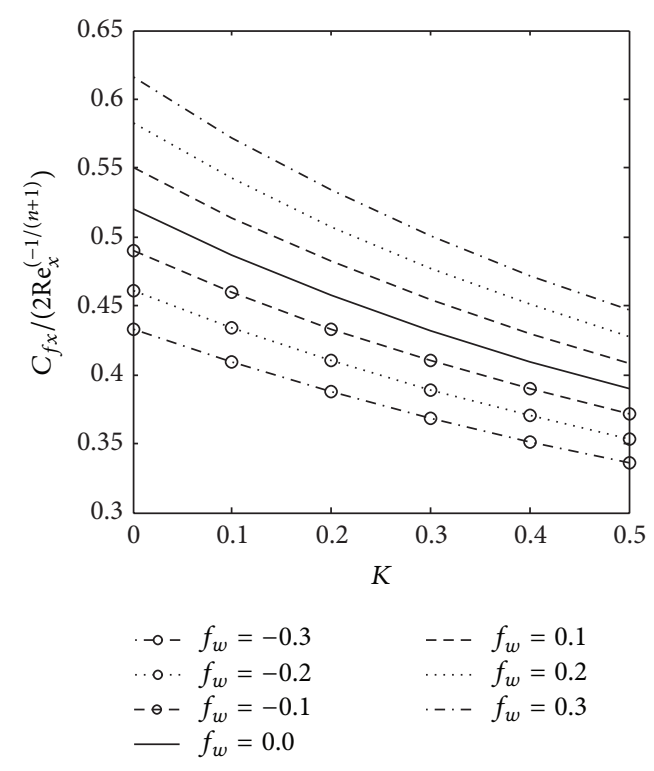

(b)

FIGURE 4: Variation of the (a) $f^{\prime}(0)$ and (b) skin friction as function of $K$ for various values of $f_{w}$ when $n=0.8$.

the presence of velocity slip, as $n$ increases, nondimensional velocity $f^{\prime}(\eta)$ increases near to the wall and then decreases away from it resulting an intersection in the velocity profile. Consequently, an increase of $n$ tends to reduce boundary layer thickness; that is, the thickness is much large for shear thinning (pseudoplastic) fluids $(0<n<1)$ than that of Newtonians $(n=1)$ and shear thickening (dilatant) fluids $(1<n<2)$. It is noted, the temperature profile enhances as $n$ increases and the power-law index $n$ has a tendency to increase the thickness of the thermal boundary layer.

Figures $4(\mathrm{a})$ and $4(\mathrm{~b})$ display variation of the $f^{\prime}(0)$ and local skin friction coefficient respectively, versus $K$ for various values of $f_{w}$ when $n=0.8$. It is interesting to note that the slip coefficient can successfully decrease local skin friction coefficient along surface. Besides, it is worth mentioning to note that the effect of velocity slip on both $f^{\prime}(0)$ and skin friction is more significant in the suction case $\left(f_{w}>0\right)$, than injection $\left(f_{w}<0\right)$, specially at high suction parameter since gradient of the $f^{\prime}(0)$ versus $K$ is much higher in the presence of suction. Furthermore, the suction/injection parameter has been potential to control velocity adjacent to the wall in the slip boundary condition problems, specially, at higher values of $K$. An increase of suction decreases nondimensional velocity at the wall while injection depicts opposite effects. Besides, injection fluid into the hydrodynamic boundary layer decreases the local skinfriction coefficient, while increasing the suction parameter enhances the local skin-friction coefficient.

The effect of the power law index parameter $n$ and $K$ on (a) fluid velocity adjacent to the wall $f^{\prime}(0)$ and (b) the local skin friction coefficientis illustrated in Figures 5(a) and 5(b), respectively. An increase of the index parameter $n$ tends to increase the fluid velocity adjacent to the wall and thereby to reduce velocity gradient at the wall. The skin friction coefficient is much larger for shear thinning (pseudoplastic) fluids $(0<n<1)$ than that of shear thickening (dilatant) fluids $(1<n<2)$, as clearly seen from Figure 5(b). The gradient of the $f^{\prime}(0)$ versus $K$ is much higher in the shear thinning fluids. Thus, it is interesting to note that the effect of partial slip on both $f^{\prime}(0)$ and skin friction is significant in shear thinning fluid $(n<1)$ then shear thickening fluid $(n>1)$. The reason goes back to the power-law index of non-Newtonian fluids based on the consistency index for non-Newtonian viscosity equation (10). Physically, for pseudoplastic non-Newtonian fluids $(n<1)$ viscosity decreases as shear rate increases (shear rate thinning). On the other hand, for dilatant $(n>1)$ viscosity increases as shear rate increases (shear rate thickening). Consequently, the effect of increasing values of power-law index parameter $n$ is to increase the fluid velocity adjacent to the wall while leading to decrease the skin friction coefficient. The computed value of Figure 5(b) can be compared here for special case $(n=$ $0.8, K=0.1$ ) with that obtained by Mahmoud [26], where $-f^{\prime \prime}(0)\left|f^{\prime \prime}(0)\right|^{n-1}$ is equal to 0.5425 and it exhibits perfect agreement.

The effect of the surface temperature parameter $k^{\prime}$ on local Nusselt number is shown in Figure 6. It is seen that local Nusselt number increases with the increase in surface temperature parameter. It is noted that the heat transfer rate increases with the increase of Prandtl number for fixed values of $K$ and $k^{\prime}$. It is interesting to note that what we can do to reach a high heat transfer rate is to use a non-Newtonian fluid with low power-law index parameter $n$. This is possible and suitable way to attain a high heat transfer rate (see Figure 7). In general the results show a decrease in the Nusselt numbers with an increase in the power law index parameter $n$ where the Nusselt number is higher for shear thinning (pseudo plastic) fluids $(0<n<1)$ than that of shear thickening 


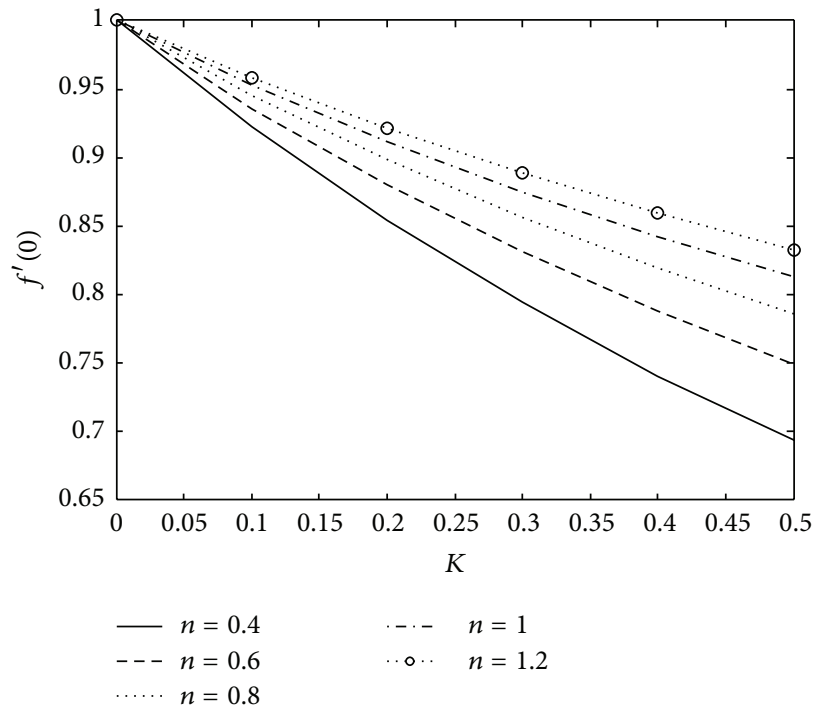

(a)

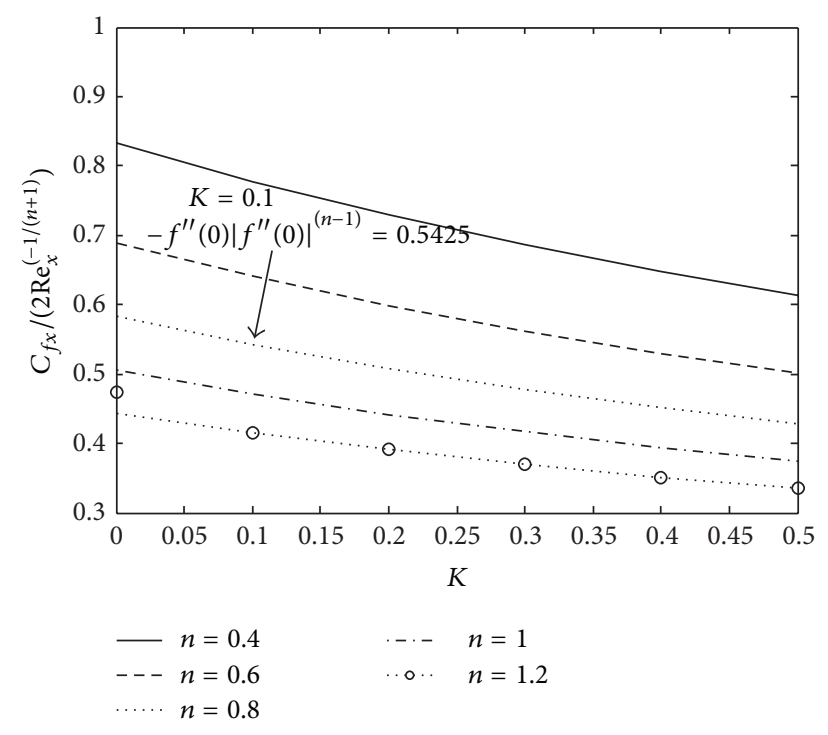

(b)

FIGURE 5: Variation of (a) $f^{\prime}(0)$ and (b) skin friction versus $K$ for various values of $n$ when $f_{w}=0.2$.

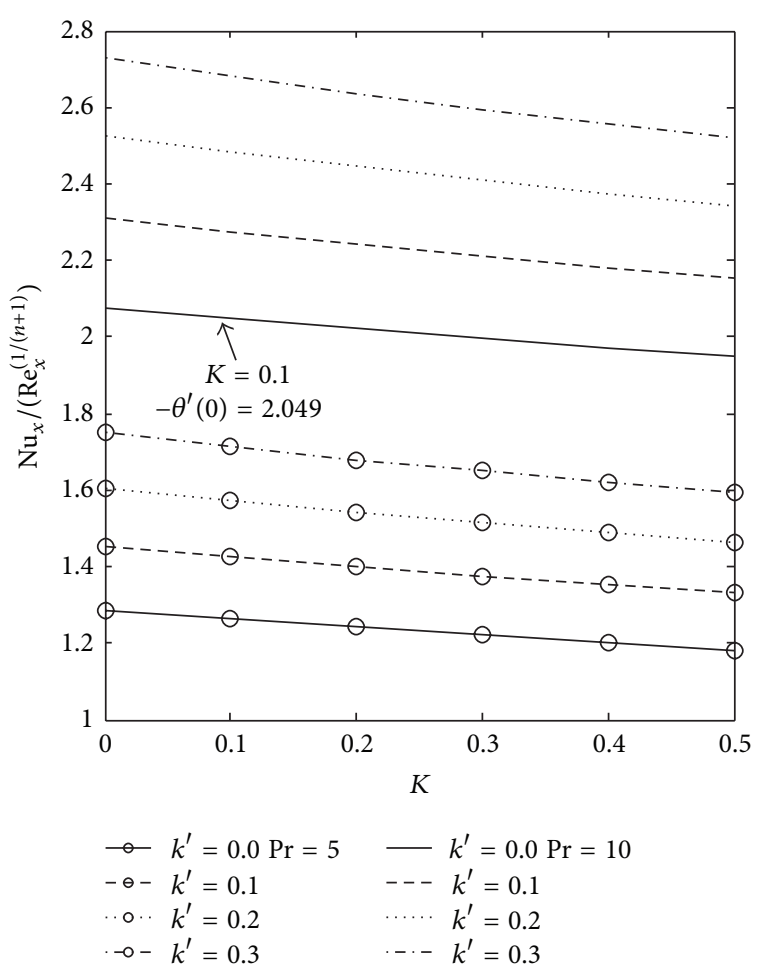

Figure 6: Local Nusselt number as function of $K$ for various values of $k^{\prime}$ and $\operatorname{Pr}$ when $f_{w}=0.2, s=0.1, n=0.8$, and $\mathrm{Ec}=0.1$.

(dilatant) fluids $(1<n<2)$. The variation of local Nusselt number as function of $K$ for various values of $f_{w}$ when $n=0.8, s=0.1, k^{\prime}=0.1, \operatorname{Pr}=5$, and Ec $=0.1$ is illustrated in Figure 8. For a fixed value of $K$ increasing suction results in an increase in the Nusselt number. Besides, the impact of increasing injection is seen to reduce the heat transfer, similar

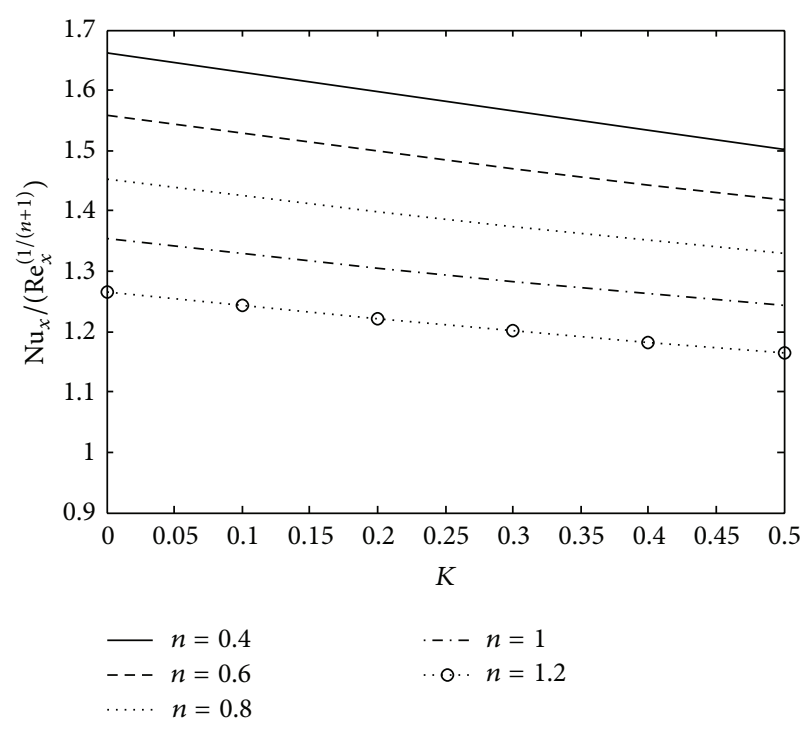

FIGURE 7: Local Nusselt number as function of $K$ for various values of $n$ when $f_{w}=0.2, s=0.1, k^{\prime}=0.1, \operatorname{Pr}=5$, and $\mathrm{Ec}=0.1$.

to the case of increasing slip coefficient. Figure 9 depicts the effect of heat generation $(s>0)$ or absorption parameter $(s<0)$ on local Nusselt number. The same consequence for the slip coefficient is illustrated; as $K$ decreases the heat transfer rate is increased. In addition, it is noted that an increase in heat generation parameter tends to decrease heat transfer rate whereas heat absorption acts in the opposite way. Physically, the reason is that the heat generation presence will enhance the fluid temperature adjacent to the wall and thus temperature gradient at the surface decreases, thus decreasing the heat transfer at the surface. But as the heat absorption increases, the local Nusselt number increases. This is because 


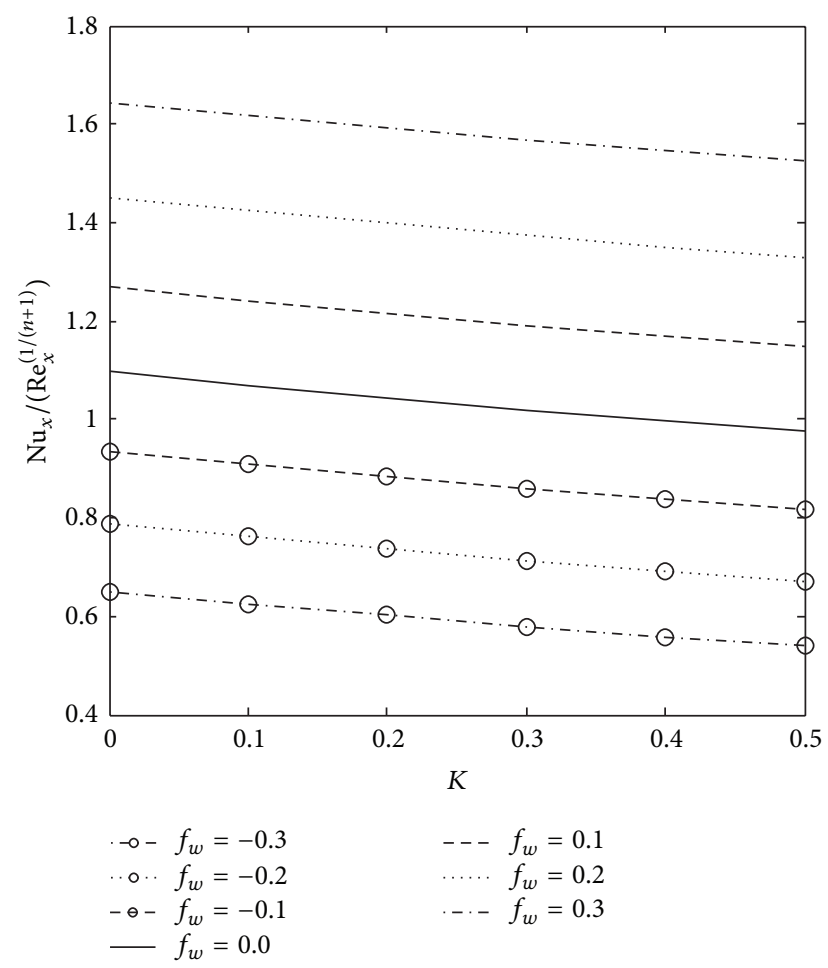

FIGURE 8: Local Nusselt number as function of $K$ for various values of $f_{w}$ when $n=0.8, s=0.1, k^{\prime}=0.1, \operatorname{Pr}=5$, and $\mathrm{Ec}=0.1$.

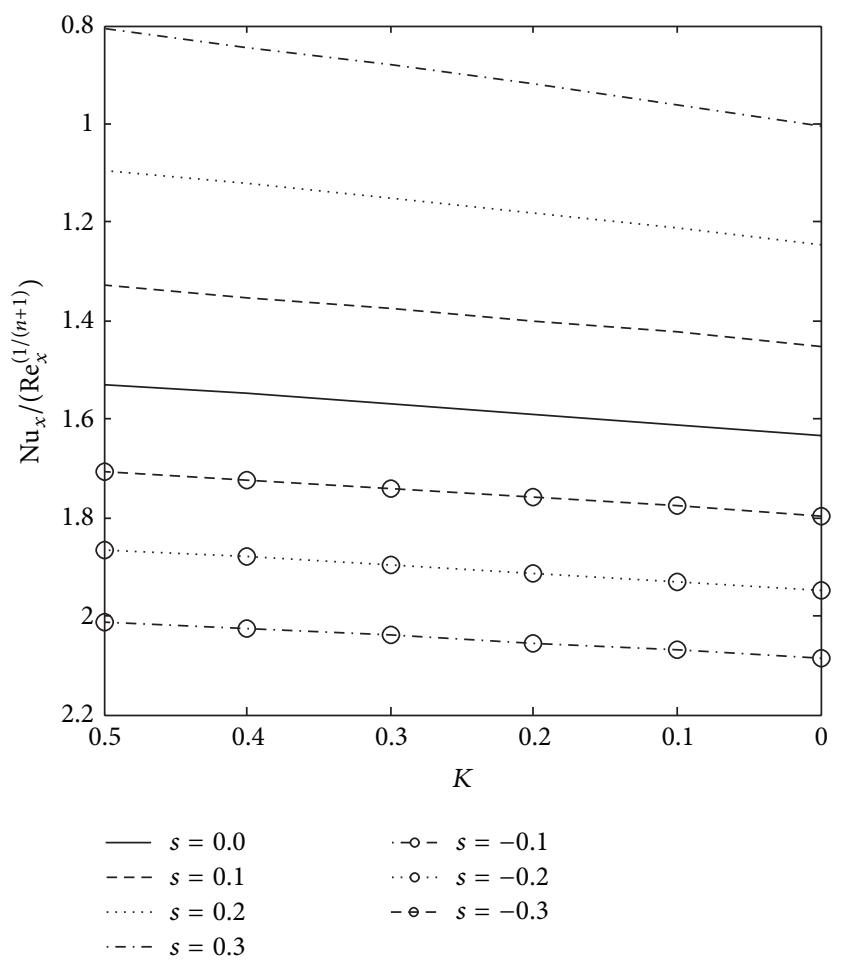

FIgURE 9: Local Nusselt number as function of $K$ for various values of $s$ when $n=0.8, f_{w}=0.2, k^{\prime}=0.1, \operatorname{Pr}=5$, and $\mathrm{Ec}=0.1$. increasing the heat absorption generates to layer of cold fluid near to the heated surface.

3.2. Effects on Entropy Generation Analysis. The following section presents the results for entropy generation analysis of power-law fluid flow over open parallel microchannels embedded within a continuously permeable moving surface at PST in the presence of heat generation/absorption and viscous dissipation. The entropy generation number as a function of the change in the number of embedded open parallel microchannels for various values of power-law index parameters, $n=0.8, n=1$, and $n=1.2$, is illustrated in Figures 10(a), 10(b), and 10(c), respectively. Here, it is demonstrated that the design of embedded open parallel microchannels yields an interesting result with respect to reduction of the entropy generation of convective heat transfer over moving surface. We know that the slip inside the open microchannels is considered, particularly in cases where a hydrophobic microchannel surface exists. First of all, it should be remembered that an increase in the slip coefficient tends to decrease both heat transfer and friction losses along a stretching surface within stationary fluid. On the other hand, the entropy generation number $N_{s}$ is comprised of friction and heat transfer irreversibilities. Thus, the entropy generation number decreases by increasing the slip coefficient in all three cases of shear thinning (pseudoplastic) fluids when $n=$ 0.8 (see Figure 10(a)), Newtonian fluid when $n=1$ (see Figure 10(b)), and shear thickening (dilatant) fluids when $n=1.2$ (see Figure 10(c)). The intersection point between the graphs in all three figures determines different trends resulting from the larger slip coefficients, as compared to the smaller slip coefficients (before the intersection point). There is an intersection point within the graphs named as "critical point." Afterward, the influence of the slip coefficient is considerable on the system and the region is called "effectual region." As a greater surface area results in an increased surface friction due to a larger number of embedded microchannels, when the slip coefficient inside the microchannels is not sufficient, an increase in the number of microchannels tends to increase the entropy generation number, due to added surface friction. This phenomenon is much more pronounced when the values of slip coefficient are less than critical point. Consequently, extra effort and cost associated with micromachining the surface to achieve a desired embedded microchannel surface cannot be warranted. However, for high values of the slip coefficient (after the critical point, inside effectual region), an increase in the number of open parallel microchannels can effectively decrease the entropy generation number. Consequently, it is necessary to consider the projected values of the slip coefficients inside the microchannels required in order to establish an appropriate design of the open parallel microchannels embedded within the moving surface due to a reduction in the exergy losses. This can be effectively achieved by considering hydrophobic open microchannels with high slip coefficients. It is interesting to note that the entropy generation number is lower for higher powerlaw index parameters, whereby the presence of the shear thinning (pseudoplastic) fluids creates entropy along the 


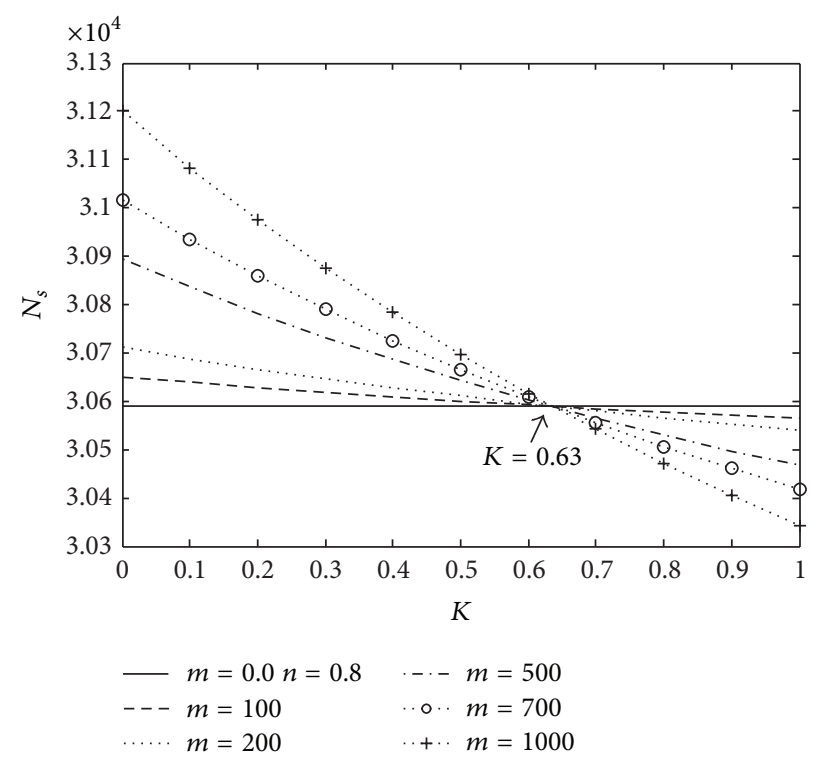

(a)

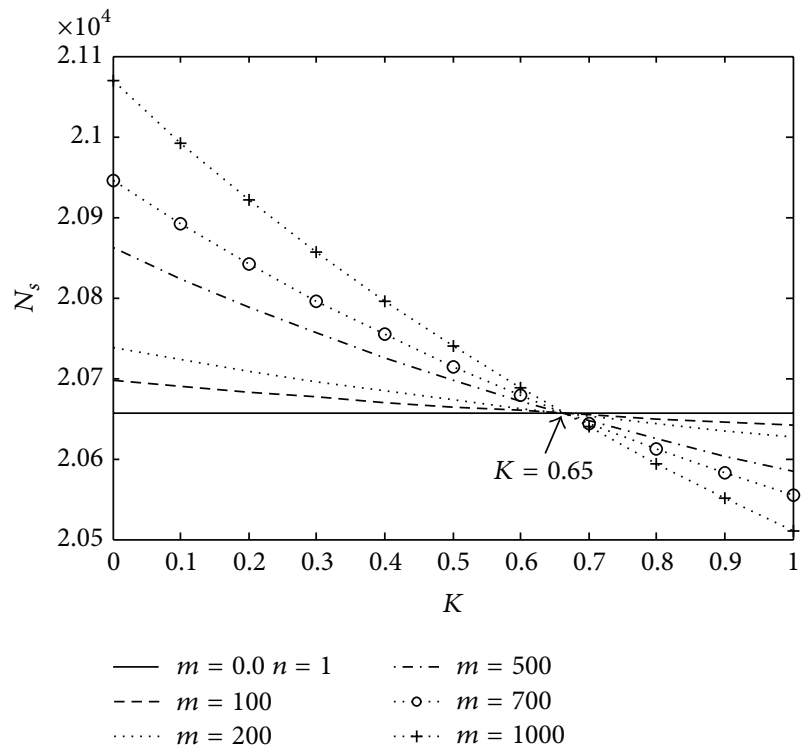

(b)

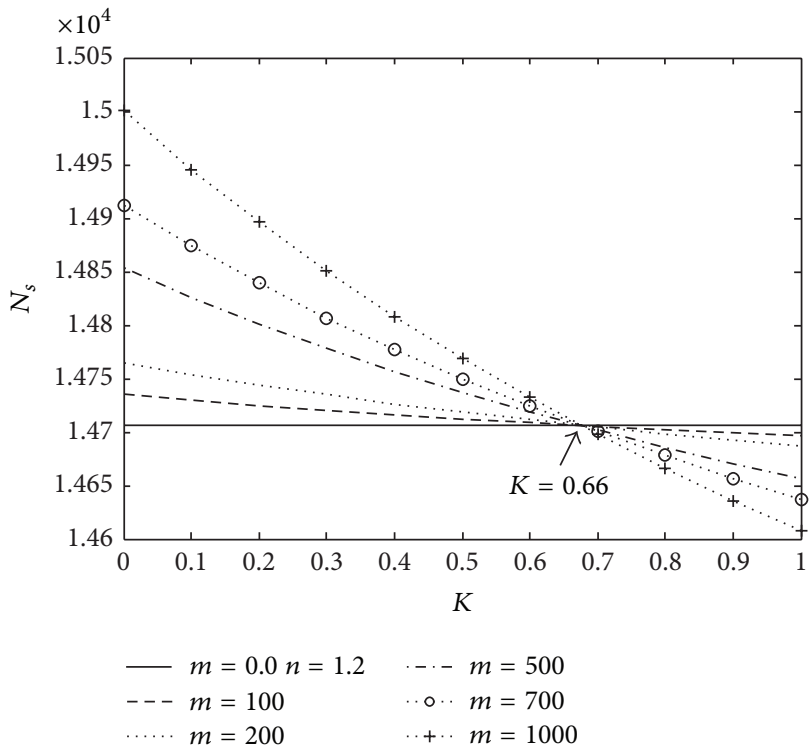

(c)

Figure 10: $N_{s}$ as a function of $K$ for various values of $m$ and (a) $n=0.8$. (b) $n=1$. (c) $n=1.2$ when $f_{w}=0.2, \operatorname{Pr}=5$, Ec $=0.1, k^{\prime}=0.1$, $s=0.1, X=0.03, \operatorname{Br} \Omega^{-1}=0.1, \operatorname{Re}=10, \zeta=0.00001$, and $\lambda=0.0001$.

surface, with a noticeable opposite effect resulting from shear thickening (dilatant) fluids. Another interesting aspect of the problem is that the critical point moves slightly rightward for higher index parameters. This means that wider range of slip coefficients can be beneficial for the shear thinning than shear thickening fluids.

Effects of number of microchannels on Bejan number for various values of power-law index parameter at $n=0.8, n=1$, and $n=1.2$ are illustrated in Figures 11(a), 11(b), and 11(c), respectively. It indicates that an increase in the number of microchannels causes an increase of the Bejan number. At high $m$, the Bejan number is high due to a small irreversibility distribution ratio $\Phi$ where the temperature irreversibilities are prominent. An increase in the number of microchannels can verify the desirable circumstances required for our system in order to reduce entropy generation where it is possible to efficiently take advantage of slip flow boundary conditions. As explained before, partial slip decreases both friction and heat transfer irreversibilities. However it is obvious from the figure that the reduction rate of friction irreversibilities is much higher compared with heat transfer irreversibilities since the Bejan number increases by $K$. It is also noted that 


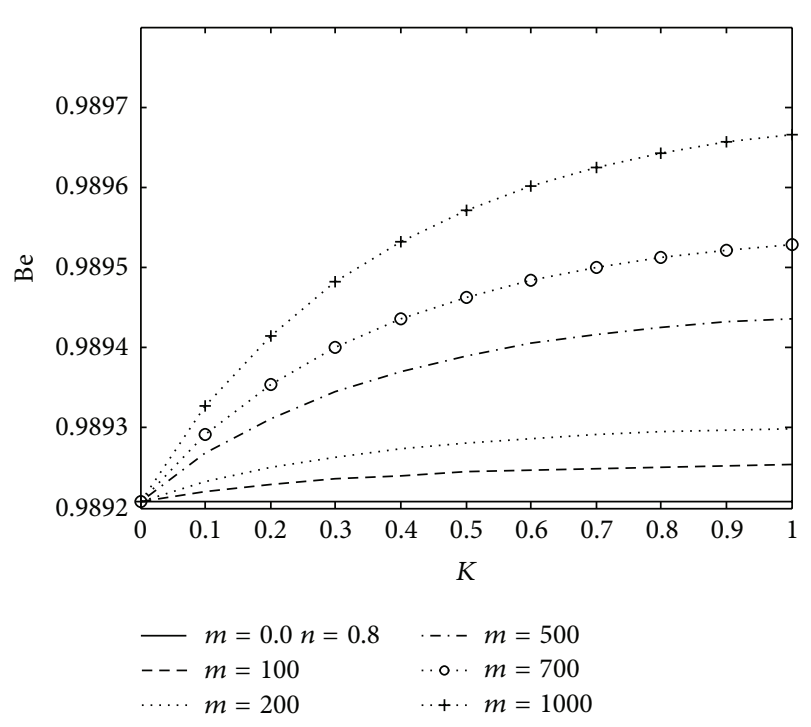

(a)

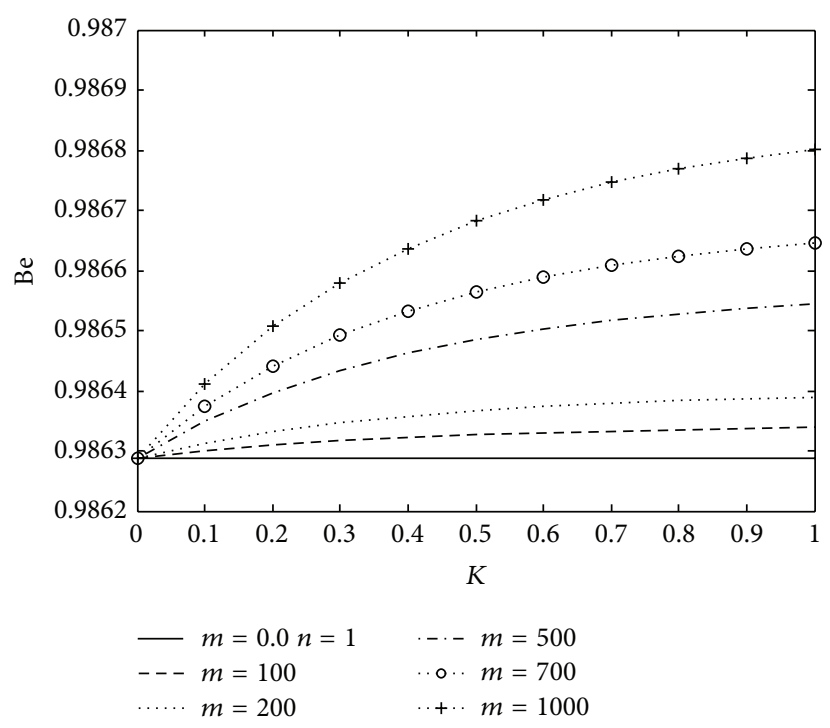

(b)

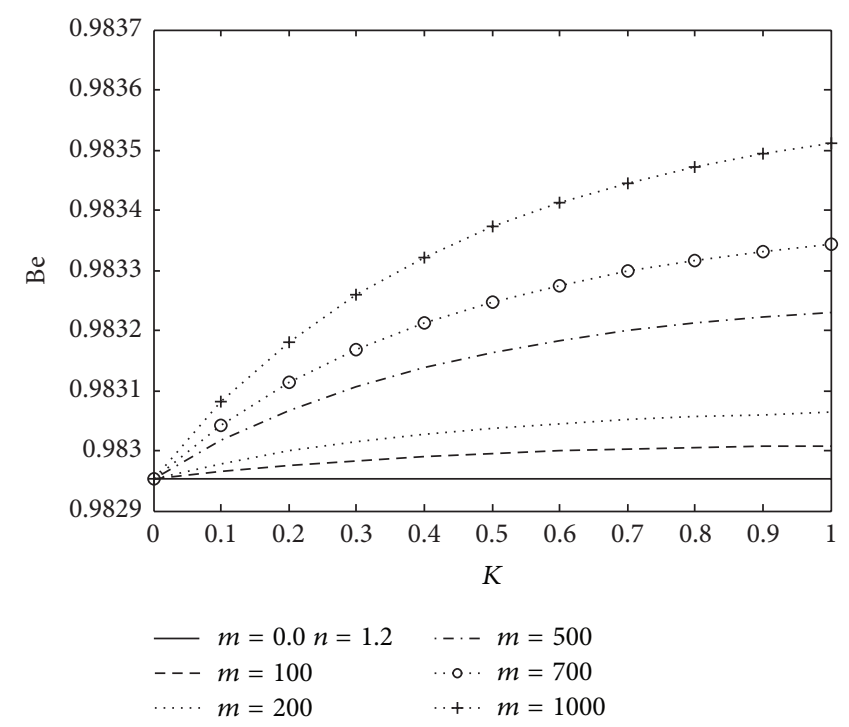

(c)

Figure 11: Bejan number versus $K$ for various values of $m$ and (a) $n=0.8$. (b) $n=1$. (c) $n=1.2$ when $f_{w}=0.2, \operatorname{Pr}=5$, Ec $=0.1, k^{\prime}=0.1$, $s=0.1, X=0.03, \operatorname{Br} \Omega^{-1}=0.1, \operatorname{Re}=10, \zeta=0.00001$, and $\lambda=0.0001$.

an increase in $n$ accompanies a slightly reduction in the Bejan number. This is because of the index parameter influences on heat transfer rate which shows a decreasing effect.

Figure 12(a) shows change of the entropy generation number with varying surface nondimensional geometric parameters and the slip coefficient. The entropy generation number shows an increase at higher microchannel depths, whereas it decreases at higher microchannel widths. This suggests that an increase in the width of the microchannels tends to enhance the slip effects along the width of the surface, causing the entropy generation number to decrease. The effect of the nondimensional geometric parameters on the Bejan number is illustrated in Figure 12(b), which it increases with the increase in $\lambda$. It indicates that an increase in the width of the microchannels decreases the irreversibility distribution ratio with the increase of heat transfer irreversibilities. Further, it is also noted that the effect of microchannel depth on Bejan number could be considered insignificant compared with the microchannel width.

The influence of the Eckert number on $N_{s}$ and Bejan number is shown in Figures 13(a) and 13(b), respectively, where it can be noted that an increase in the Ec results in a decrease in the both $N_{s}$ and Be as the heat transfer irreversibility decreases. Figures 14(a) and 14(b) display the effect of the suction/injection parameter on the entropy generation number and Bejan number, respectively, for various values 


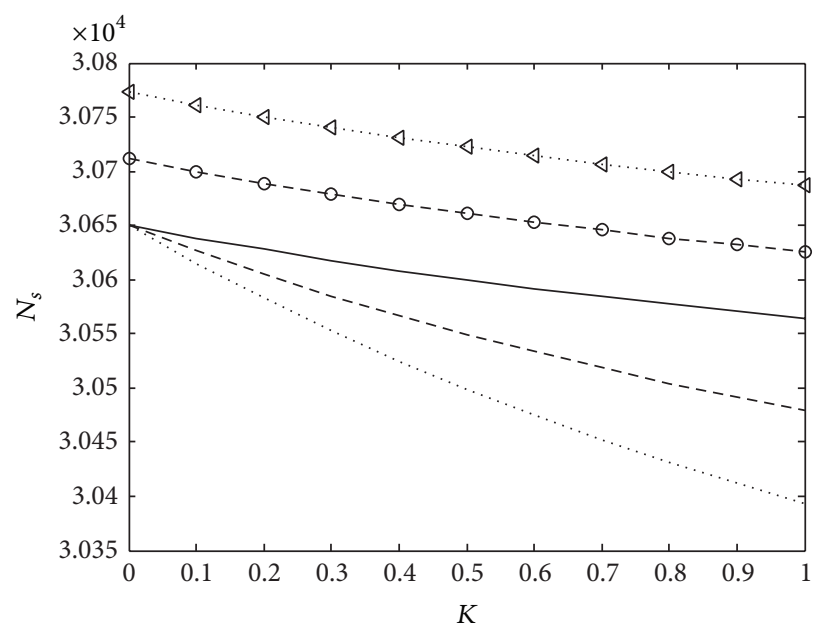

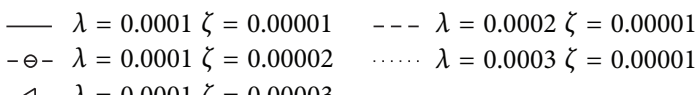
$\therefore \triangleleft \cdots \quad \lambda=0.0001 \zeta=0.00003$

(a)

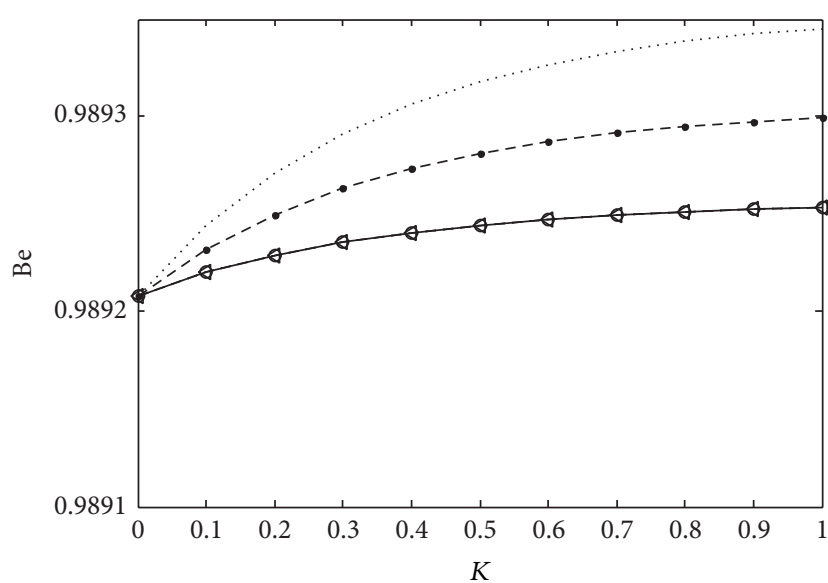

$\lambda=0.0001 \zeta=0.00001 \quad--\lambda=0.0002 \zeta=0.00001$ $-\ominus-\lambda=0.0001 \zeta=0.00002 \quad \ldots \ldots \lambda=0.0003 \zeta=0.00001$

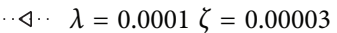

(b)

Figure 12: (a) $N_{s}$ as a function of $K$ for various values of $\zeta$ and $\lambda$ when $n=0.8, f_{w}=0.2, \operatorname{Pr}=5$, Ec $=0.1, k^{\prime}=0.1, s=0.1, m=100$, $X=0.03, \operatorname{Br} \Omega^{-1}=0.1$, and $\operatorname{Re}=10$. (b) Bejan number as a function of $K$ for various values of $\zeta$ and $\lambda$ when $n=0.8, f_{w}=0.2, \operatorname{Pr}=5$, $\mathrm{Ec}=0.1, k^{\prime}=0.1, s=0.1, m=100, X=0.03, \mathrm{Br} \Omega^{-1}=0.1$, and $\operatorname{Re}=10$.

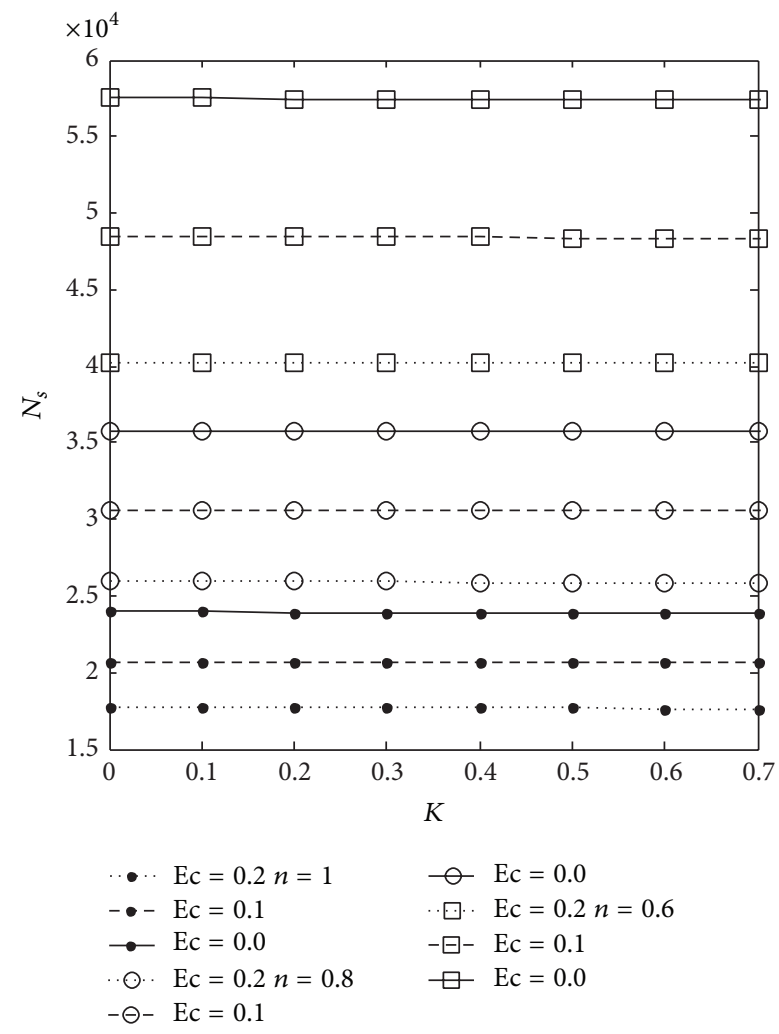

(a)

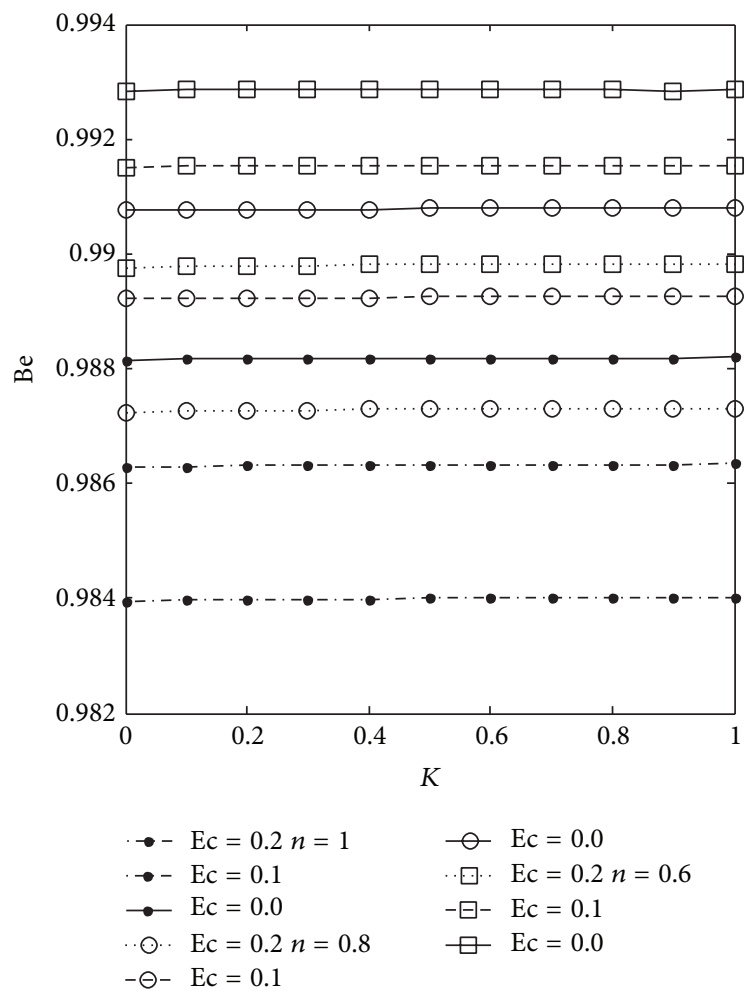

(b)

Figure 13: (a) $N_{s}$ as a function of $K$ for various values of Ec and $n$ when $f_{w}=0.2, \operatorname{Pr}=5, k^{\prime}=0.1, s=0.1, X=0.03, m=100, \operatorname{Br} \Omega^{-1}=0.1$, $\operatorname{Re}=10, \zeta=0.00001$, and $\lambda=0.0001$. (b) Bejan number as a function of $K$ for various values of Ec and $n$ when $n=0.8, f_{w}=0.2, \operatorname{Pr}=5$, $k^{\prime}=0.1, s=0.1, X=0.03, m=100, \operatorname{Br} \Omega^{-1}=0.1, \operatorname{Re}=10, \zeta=0.00001$, and $\lambda=0.0001$. 


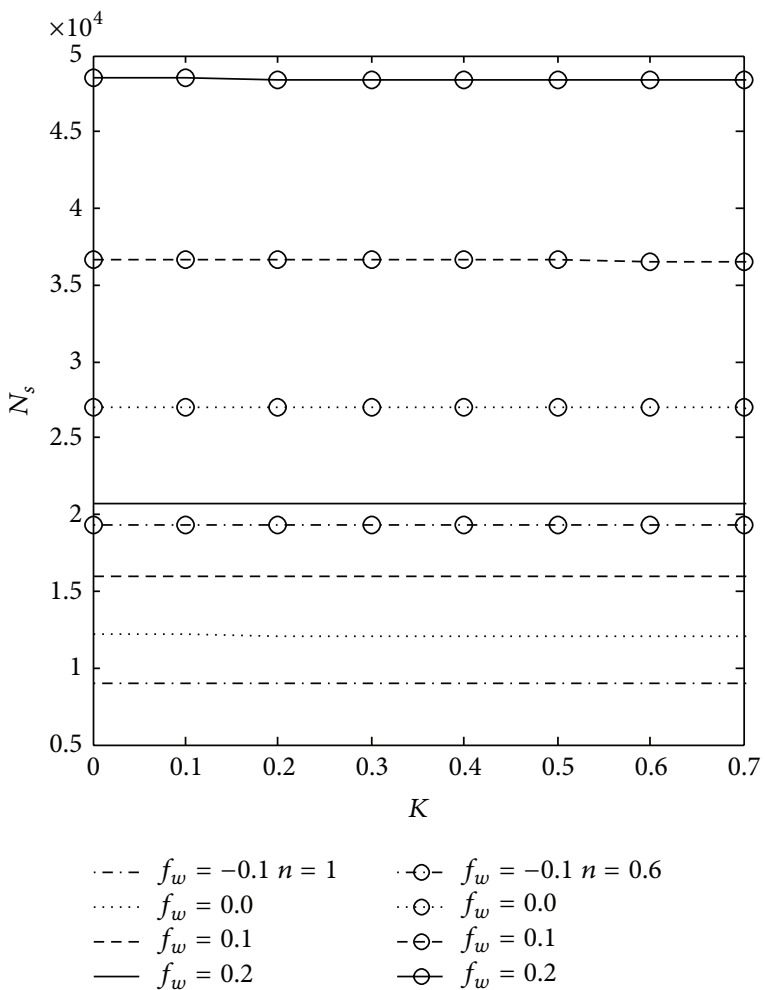

(a)

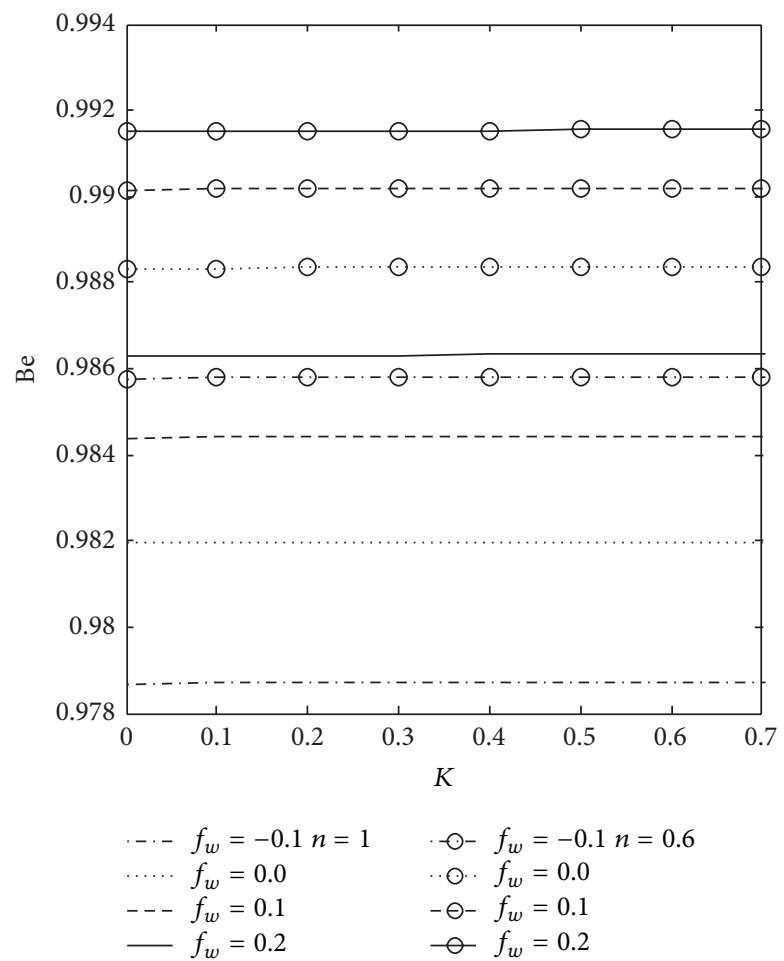

(b)

Figure 14: (a) $N_{s}$ as a function of $K$ for various values of $f_{w}$ and $n$ when $\operatorname{Pr}=5, \mathrm{Ec}=0.1, k^{\prime}=0.1, s=0.1, X=0.03, m=100, \mathrm{Br} \Omega^{-1}=0.1$, $\operatorname{Re}=10, \zeta=0.00001$, and $\lambda=0.0001$. (b) Bejan number as a function of $K$ for various values of $f_{w}$ and $n$ when $\operatorname{Pr}=5, \mathrm{Ec}=0.1, k^{\prime}=0.1$, $s=0.1, X=0.03, m=100, \operatorname{Br} \Omega^{-1}=0.1, \operatorname{Re}=10, \zeta=0.00001$, and $\lambda=0.0001$.

of power-law index parameters. The presence of the suction creates entropy along the surface, with a noticeable opposite effect resulting from injection. Moreover, Bejan number decreases when $f_{w}$ is increased for injection. It is also evident that Bejan number is increased in the case of suction, when compared to the injection. The suction/injection parameters can be more significant on the system for lower index parameters since the profiles are closer to each other when $n=1$.

\section{Conclusion}

This study is focused on entropy generation analysis of power-law non-Newtonian fluid flow over open parallel microchannels embedded within a continuously permeable moving surface at PST in the presence of heat generation/absorption and viscous dissipation. The heat transfer results suggest that the Nusselt number is increased with the surface temperature parameter, Prandtl number, internal heat absorption, and suction, whereas it is decreased with the slip coefficient, power-law index parameter, heat generation, and injection. After that, based on EBSM, the entropy generation number is formulated by an integral of local entropy generation rate on the width of the surface. It is noted that the entropy generation number decreases by increasing the slip coefficient in all three cases of shear thinning fluids, Newtonian fluid, and shear thickening fluids. It is interesting to note that for high values of the slip coefficient (after the critical point), an increase in the number of open parallel microchannels $(m)$ can effectively reduce the entropy production. Thus, the results demonstrate that, in the present surface microprofiling design, the value of slip coefficient $K$ is suggested to be selected more than critical point, reaching an effective reduction in entropy generation by increasing number of microchannels. Moreover, $N_{s}$ decreases with the increase of injection, Ec and $\lambda$, while it increases with the increase of suction and $\zeta$. It is hoped that the present work can be used for understanding more complex surface problems regarding the manipulation of non-Newtonian fluids in fluid mechanic systems.

\section{Conflict of Interests}

The authors declare that there is no conflict of interests regarding the publication of this paper.

\section{References}

[1] J. H. Kim and J. Y. Yoon, "Protein adsorption on polymer particles," in Encyclopedia of Surface and Colloidal Science, T. A. Hubbard, Ed., pp. 4373-4381, Marcel Dekker, New York, NY, USA, 2002. 
[2] R. D. Johnson, V. G. Gavalas, S. Daunert, and L. G. Bachas, "Microfluidic ion-sensing devices," Analytica Chimica Acta, vol. 613, no. 1, pp. 20-30, 2008.

[3] J. Jang and S. S. Lee, "Theoretical and experimental study of MHD (magnetohydrodynamic) micropump," Sensors and Actuators A: Physical, vol. 80, no. 1, pp. 84-89, 2000.

[4] B. D. Iverson and S. V. Garimella, "Recent advances in microscale pumping technologies: a review and evaluation," Microfluidics and Nanofluidics, vol. 5, no. 2, pp. 145-174, 2008.

[5] P. Chaturani and V. R. Ponnalagar Samy, "A study of nonNewtonian aspects of blood flow through stenosed arteries and its applications in arterial diseases," Biorheology, vol. 22, no. 6, pp. 521-531, 1985.

[6] M. H. Yazdi, S. Abdullah, I. Hashim, K. Sopian, and A. Zaharim, "Entropy generation analysis of liquid fluid past embedded open parallel microchannels within the surface," European Journal of Scientific Research, vol. 28, no. 3, pp. 462-470, 2009.

[7] M. H. Yazdi, S. Abdullah, I. Hashim, and K. Sopian, "Entropy generation analysis of open parallel microchannels embedded within a permeable continuous moving surface: application to magnetohydrodynamics (MHD)," Entropy, vol. 14, no. 1, pp. 123, 2012.

[8] M. H. Yazdi, S. Abdullah, I. Hashim, and K. Sopian, "Second law analysis of mhd flow over open parallel microchannels embedded in a micropatterned surface," in Proceedings of 10th WSEAS International Conference on Heat Transfer, Thermal Engineering and Environment, Istanbul, Turkey, August 2012.

[9] R. P. Chhabra and J. F. Richardson, Non-Newtonian Flow: Fundamentals and Engineering Applications, ButterworthHeinemann, 1999.

[10] T. Hayat, Z. Iqbal, M. Qasim, and S. Obaidat, "Steady flow of an Eyring Powell fluid over a moving surface with convective boundary conditions," International Journal of Heat and Mass Transfer, vol. 55, no. 7-8, pp. 1817-1822, 2012.

[11] E. G. Fisher, Extrusion of Plastics, Iliffe Books, New York, NY, USA, 1964.

[12] L. Capretto, W. Cheng, M. Hill, and X. Zhang, "Micromixing within microfluidic devices," Topics in Current Chemistry, vol. 304, pp. 27-68, 2011.

[13] M. H. Yazdi, S. Abdullah, I. Hashim, A. Zaharim, and K. Sopian, "Friction and heat transfer in slip flow boundary layer at constant heat flux boundary conditions," in Mathematical Methods, Computational Techniques, Non-Linear Systems, Intelligent Systems, pp. 207-212, 2008.

[14] M. H. Yazdi, S. Abdullah, I. Hashim, Z. M. Nopiah, A. Zaharim, and K. Sopian, "Convective heat transfer of slip liquid flow past horizontal surface within the porous media at constant heat flux boundary conditions," in Proceedings of the American Conference on Applied Mathematics: Recent Advances in Applied Mathematics, pp. 527-533, 2009.

[15] M. H. Yazdi, S. Abdullah, I. Hashim, and K. Sopian, "Slip MHD liquid flow and heat transfer over non-linear permeable stretching surface with chemical reaction," International Journal of Heat and Mass Transfer, vol. 54, no. 15-16, pp. 3214-3225, 2011.

[16] M. H. Yazdi, S. Abdullah, I. Hashim, and K. Sopian, "Slip MHD flow over permeable stretching surface with chemical reaction," in Proceedings of the 17th Australasian Fluid Mechanics Conference (17AFMC '10), pp. 55-58, Auckland, New Zealand, December 2010.

[17] M. Mahmoud and S. Waheed, "Effects of slip and heat generation/absorption on MHD mixed convection flow of a micropolar fluid over a heated stretching surface," Mathematical Problems in Engineering, vol. 2010, Article ID 579162, 20 pages, 2010.

[18] M. H. Yazdi, S. Abdullah, I. Hashim, and K. Sopian, "Effects of viscous dissipation on the slip MHD flow and heat transfer past a permeable surface with convective boundary conditions," Energies, vol. 4, no. 12, pp. 2273-2294, 2011.

[19] B. Vujanovic, A. M. Strauss, and D. Djukić, "A variational solution of the Rayleigh problem for a power law non-Newtonian conducting fluid," Archive of Applied Mechanics, vol. 41, no. 6, pp. 381-386, 1971.

[20] K. V. Prasad, D. Pal, and P. S. Datti, "MHD power-law fluid flow and heat transfer over a non-isothermal stretching sheet," Communications in Nonlinear Science and Numerical Simulation, vol. 14, no. 5, pp. 2178-2189, 2009.

[21] W. Schowalter, "The application of boundary-layer theory to power-law pseudoplastic fluids: similar solutions," AIChE Journal, vol. 6, no. 1, pp. 24-28, 1960.

[22] A. Acrivos, M. Shah, and E. Petersen, "Momentum and heat transfer in laminar boundary-layer flows of non-Newtonian fluids past external surfaces," AIChE Journal, vol. 6, no. 2, pp. 312-317, 1960.

[23] I. A. Hassanien, A. A. Abdullah, and R. S. R. Gorla, "Flow and heat transfer in a power-law fluid over a nonisothermal stretching sheet," Mathematical and Computer Modelling, vol. 28, no. 9, pp. 105-116, 1998.

[24] M. A. A. Mahmoud and M. A.-E. Mahmoud, "Analytical solutions of hydromagnetic boundary-layer flow of a nonNewtonian power-law fluid past a continuously moving surface," Acta Mechanica, vol. 181, no. 1-2, pp. 83-89, 2006.

[25] M. Jalil, S. Asghar, and M. Mushtaq, "Analytical solutions of the boundary layer flow of power-law fluid over a power-law stretching surface," Communications in Nonlinear Science and Numerical Simulation, vol. 18, no. 5, pp. 1143-1150, 2013.

[26] M. A. A. Mahmoud, "Slip velocity effect on a non-Newtonian power-law fluid over a moving permeable surface with heat generation," Mathematical and Computer Modelling, vol. 54, no. 5-6, pp. 1228-1237, 2011.

[27] W. Ibrahim and B. Shanker, "Unsteady MHD mixed convective boundary-layer slip flow and heat transfer with thermal radiation and viscous dissipation," Heat Transfer-Asian Research, vol. 43, no. 5, pp. 412-426, 2014.

[28] S. Mukhopadhyay, "Slip effects on MHD boundary layer flow over an exponentially stretching sheet with suction/blowing and thermal radiation," Ain Shams Engineering Journal, vol. 4, no. 3, pp. 485-491, 2013.

[29] K. Vajravelu, K. Prasad, P. Datti, and B. Raju, "MHD flow and heat transfer of an Ostwald-de Waele fluid over an unsteady stretching surface," Ain Shams Engineering Journal, vol. 5, no. 1, pp. 157-167, 2013.

[30] S. Mahmud and R. A. Fraser, "The second law analysis in fundamental convective heat transfer problems," International Journal of Thermal Sciences, vol. 42, no. 2, pp. 177-186, 2003.

[31] S. Aïboud and S. Saouli, "Entropy analysis for viscoelastic magnetohydrodynamic flow over a stretching surface," International Journal of Non-Linear Mechanics, vol. 45, no. 5, pp. 482-489, 2010.

[32] A. Réveillère and A. C. Baytaş, "Minimum entropy generation for laminar boundary layer flow over a permeable plate," International Journal of Exergy, vol. 7, no. 2, pp. 164-177, 2010. 
[33] A. S. Eegunjobi and O. D. Makinde, "Entropy generation analysis in a variable viscosity MHD channel flow with permeable walls and convective heating," Mathematical Problems in Engineering, vol. 2013, Article ID 630798, 12 pages, 2013.

[34] B. Sagot, G. Antonini, and F. Buron, "Enhancement of jetto-wall heat transfer using axisymmetric grooved impinging plates," International Journal of Thermal Sciences, vol. 49, no. 6 , pp. 1026-1030, 2010.

[35] S. Lim and H. Choit, "Optimal shape design of a pressuredriven curved micro channel," in Proceeding of the 42nd AIAA Aerospace Sciences Meeting and Exhibit, pp. 6078-6085, Carson City, Nev, USA, January 2004.

[36] G. F. Naterer, "Adaptive surface microprofiling for microfluidic energy conversion," Journal of Thermophysics and Heat Transfer, vol. 18, no. 4, pp. 494-501, 2004.

[37] G. F. Naterer, "Surface micro-profiling for reduced energy dissipation and exergy loss in convective heat transfer," Microscale Thermophysical Engineering, vol. 9, no. 3, pp. 213-236, 2005.

[38] G. F. Naterer, "Reducing energy availability losses with open parallel microchannels embedded in a micropatterned surface," International Journal of Energy Research, vol. 29, no. 13, pp. 12151229, 2005.

[39] G. F. Naterer and S. R. Chomokovski, "Entropy-based surface microprofiling for passive near-wall flow control," Journal of Micromechanics and Microengineering, vol. 17, no. 10, pp. 21382147, 2007.

[40] G. F. Naterer, P. S. Glockner, D. Thiele, S. Chomokovski, G. Venn, and G. Richardson, "Surface micro-grooves for near-wall exergy and flow control: application to aircraft intake de-icing," Journal of Micromechanics and Microengineering, vol. 15, no. 3, pp. 501-513, 2005.

[41] M. H. Yazdi, S. Abdullah, and I. Hashim, "Reducing entropy generation in MHD fluid flow over open parallel microchannels embedded in a micropatterned permeable surface," Entropy, vol. 15, no. 11, pp. 4822-4843, 2013.

[42] W. Wu, P. R. Selvaganapathy, and C. Y. Ching, "Transport of particles and microorganisms in microfluidic channels using rectified ac electro-osmotic flow," Biomicrofluidics, vol. 5, no. 1, Article ID 013407, 2011.

[43] Z. Wu and N. T. Nguyen, Passive and Active Micromixers, Micro Process Engineering: A Comprehensive Handbook, vol. 1, Wiley, New York, NY, USA, 2009.

[44] W. Wu, D. Ewing, C. Y. Ching, and P. R. Selvaganapathy, "Measurement of periodic micro flows using micro-particle image velocimetry with phase sampling," Microfluidics and Nanofluidics, vol. 15, no. 1, pp. 127-135, 2013.

[45] D. C. Tretheway and C. D. Meinhart, "Apparent fluid slip at hydrophobic microchannel walls," Physics of Fluids, vol. 14, no. 3, pp. L9-L12, 2002.

[46] F. P. Foraboschi and I. Di Federico, "Heat transfer in laminar flow of non-Newtonian heat-generating fluids," International Journal of Heat and Mass Transfer, vol. 7, no. 3, pp. 315-325, 1964.

[47] B. Sakiadis, "Boundary-layer behavior on continuous solid surfaces: I. Boundary-layer equations for two-dimensional and axisymmetric flow," AIChE Journal, vol. 7, no. 1, pp. 26-28, 1961.

[48] L. C. Woods, The Thermodynamics of Fluid Systems, Oxford University Press, 1985.

[49] W. A. Khan and R. S. R. Gorla, "Second law analysis for free convection in non-Newtonian fluids over a horizontal plate embedded in a porous medium: prescribed surface temperature," Journal of Heat Transfer, vol. 133, no. 5, Article ID 052601, 2011.
[50] Y.-M. Hung, "Viscous dissipation effect on entropy generation for non-Newtonian fluids in microchannels," International Communications in Heat and Mass Transfer, vol. 35, no. 9, pp. 1125-1129, 2008.

[51] V. Fox, L. Erickson, and L. Fan, "Methods for solving the boundary layer equations for moving continuous flat surfaces with suction and injection," AIChE Journal, vol. 14, no. 5, pp. 726-736, 1968.

[52] C. H. Chen, "Forced convection over a continuous sheet with suction or injection moving in a flowing fluid," Acta Mechanica, vol. 138, no. 1-2, pp. 1-11, 1999.

[53] A. Jacobi, "A scale analysis approach to the correlation of continuous moving sheet (backward boundary layer) forced convective heat transfer," Journal of Heat Transfer, vol. 115, no. 4, pp. 1058-1061, 1993.

[54] S. Mahmud and R. A. Fraser, "Second law analysis of forced convection in a circular duct for non-Newtonian fluids," Energy, vol. 31, no. 12, pp. 2226-2244, 2006.

[55] M. H. Yazdi, I. Hashim, and K. Sopian, "Slip boundary layer flow of a power-law fluid over moving permeable surface with viscous dissipation and prescribed surface temperature," International Review of Mechanical Engineering, vol. 8, no. 7, 2014. 


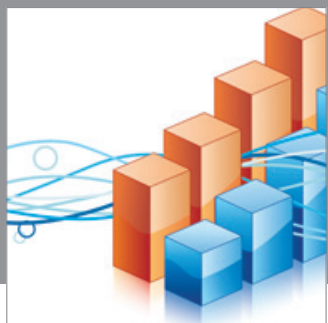

Advances in

Operations Research

mansans

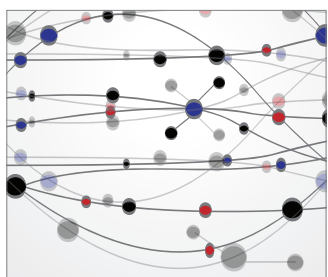

The Scientific World Journal
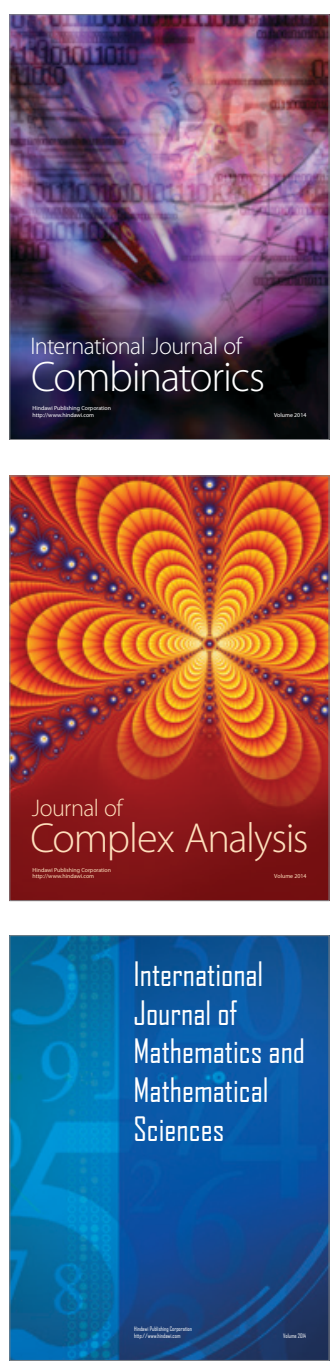
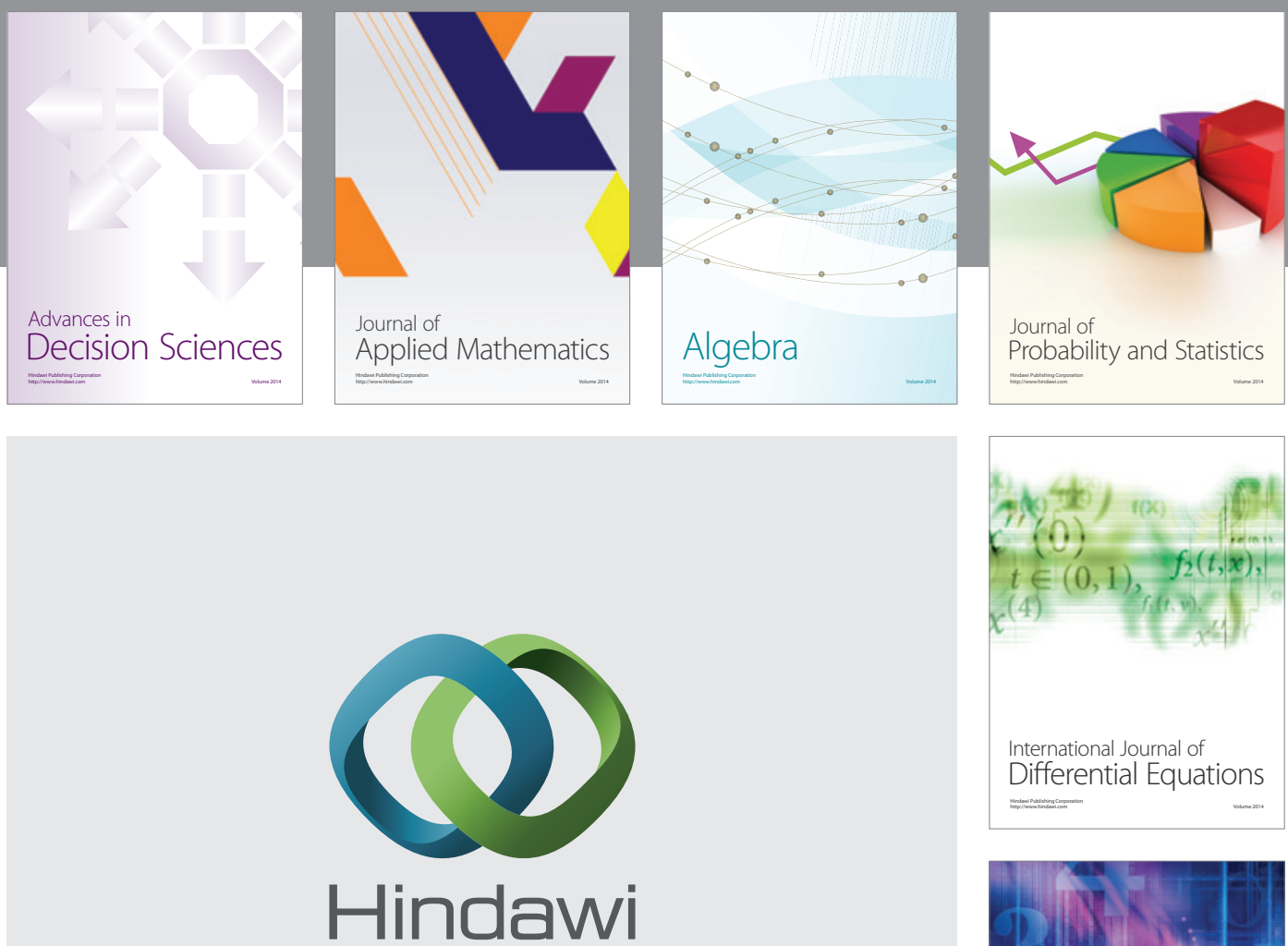

Submit your manuscripts at http://www.hindawi.com
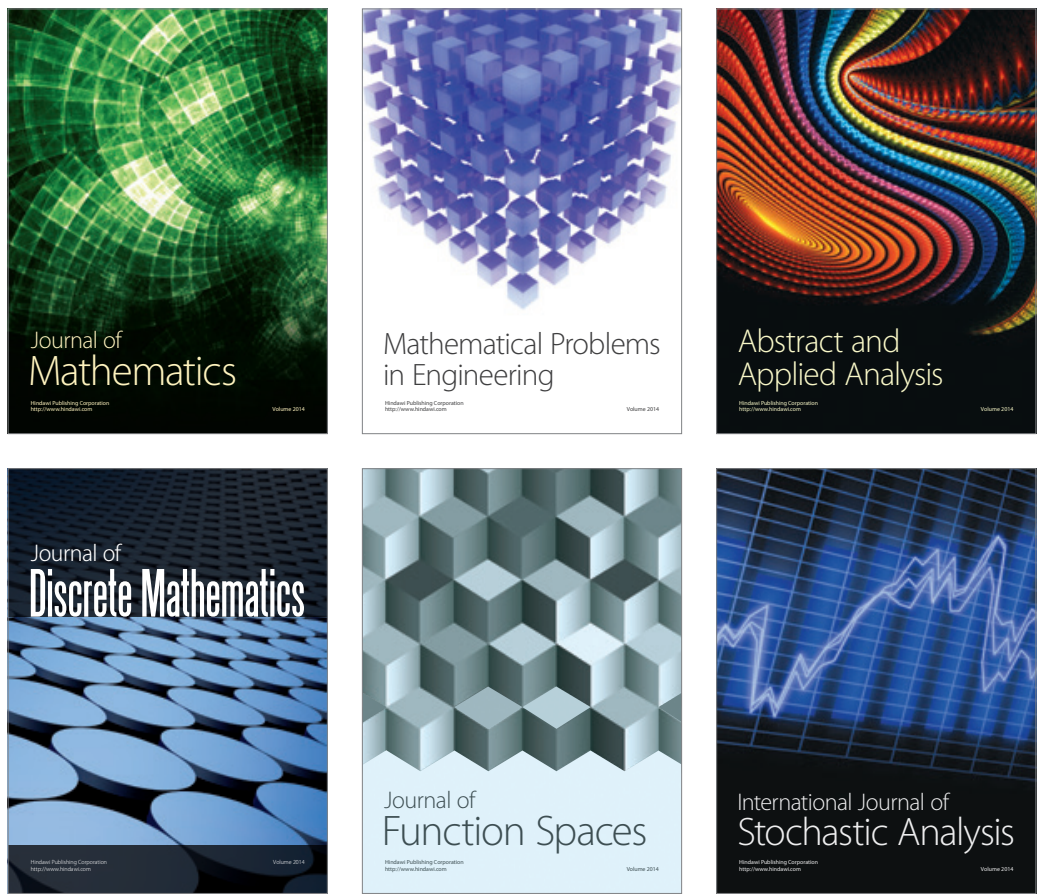

Journal of

Function Spaces

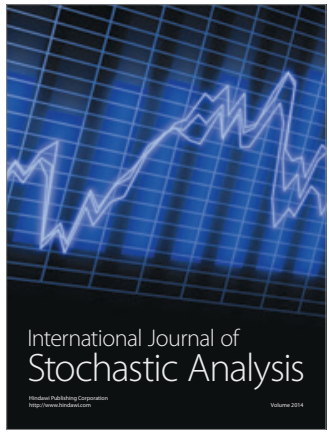

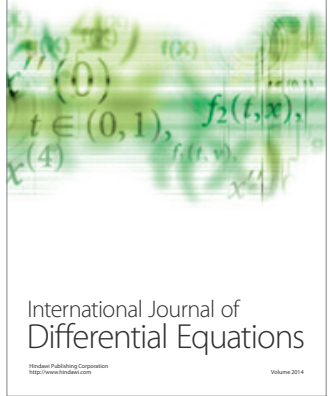
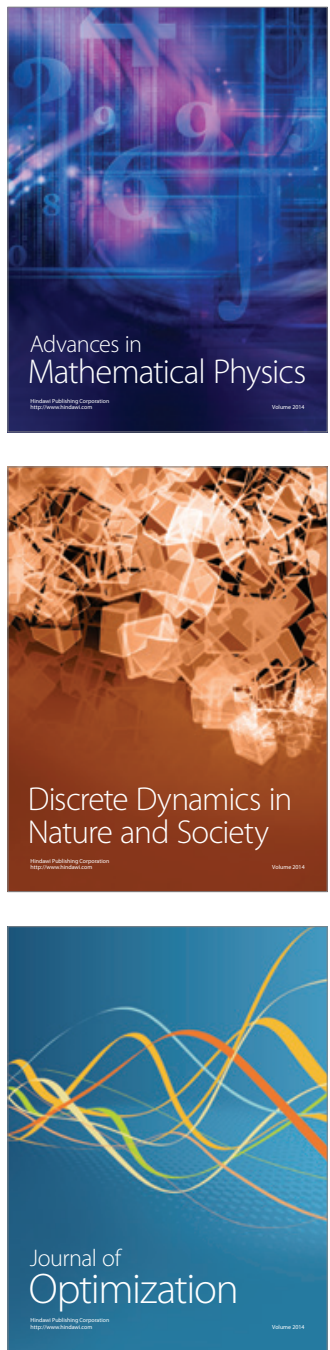